\title{
Early-stage heart failure with preserved ejection fraction in the pig: a cardiovascular magnetic resonance study
}

Ursula Reiter $^{1^{* \dagger}}$, Gert Reiter ${ }^{2 \dagger}$, Martin Manninger ${ }^{3}$, Gabriel Adelsmayr ${ }^{1}$, Julia Schipke ${ }^{4}$, Alessio Alogna ${ }^{3,5}$, Alexandra Rajces ${ }^{4}$, Aurelien F. Stalder ${ }^{6}$, Andreas Greiser ${ }^{6}$, Christian Mühlfeld ${ }^{4}$, Daniel Scherr ${ }^{3}$, Heiner Post ${ }^{5}$, Burkert Pieske $e^{3,5,7,8}$ and Michael Fuchsjäger ${ }^{1}$

\begin{abstract}
Background: The hypertensive deoxy-corticosterone acetate (DOCA)-salt-treated pig (hereafter, DOCA pig) was recently introduced as large animal model for early-stage heart failure with preserved ejection fraction (HFpEF). The aim of the present study was to evaluate cardiovascular magnetic resonance (CMR) of DOCA pigs and weightmatched control pigs to characterize ventricular, atrial and myocardial structure and function of this phenotype model.

Methods: Five anesthetized DOCA and seven control pigs underwent 3 T CMR at rest and during dobutamine stress. Left ventricular/atrial (LV/LA) function and myocardial mass (LVMM), strains and torsion were evaluated from (tagged) cine imaging. 4D phase-contrast measurements were used to assess blood flow and peak velocities, including transmitral early-diastolic (E) and myocardial tissue (E') velocities and coronary sinus blood flow. Myocardial perfusion reserve was estimated from stress-to-rest time-averaged coronary sinus flow. Global native myocardial T1 times were derived from prototype modified Look-Locker inversion-recovery (MOLLI) short-axis T1 maps. After in-vivo measurements, transmural biopsies were collected for stereological evaluation including the volume fractions of interstitium $\left(V_{V}(\right.$ int $\left./ L V)\right)$ and collagen $\left(V_{V}(\right.$ coll/LV)). Rest, stress, and stress-to-rest differences of cardiac and myocardial parameters in DOCA and control animals were compared by $t$-test.
\end{abstract}

Results: In DOCA pigs LVMM $(p<0.001)$ and LV wall-thickness (end-systole/end-diastole, $p=0.003 / p=0.007$ ) were elevated. During stress, increase of LV ejection-fraction and decrease of end-systolic volume accounted for normal contractility reserves in DOCA and control pigs. Rest-to-stress differences of cardiac index $(p=0.040)$ and end-diastolic volume $(p=0.042)$ were documented. Maximal $(p=0.042)$ and minimal $(p=0.012)$ LA volumes in DOCA pigs were elevated at rest; total LA ejection-fraction decreased during stress $(p=0.006)$. $E^{\prime}$ was lower in DOCA pigs, corresponding to higher $E / E^{\prime}$ at rest $(p=0.013)$ and stress $(p=0.026)$. Myocardial perfusion reserve was reduced in DOCA pigs $(p=0.031)$. T1-times and $V_{V}($ int $/ L V)$ did not differ between groups, whereas $V_{V}(c o l / / L V)$ levels were higher in DOCA pigs $(p=0.044)$.

Conclusions: LA enlargement, $E^{\prime}$ and $E / E^{\prime}$ were the markers that showed the most pronounced differences between DOCA and control pigs at rest. Inadequate increase of myocardial perfusion reserve during stress might represent a metrics for early-stage HFpEF. Myocardial T1 mapping could not detect elevated levels of myocardial collagen in this model.

(Continued on next page)

\footnotetext{
* Correspondence: ursula.reiter@medunigraz.at

${ }^{\dagger}$ Equal contributors

'Division of General Radiology, Department of Radiology, Medical University

of Graz, Auenbruggerplatz 9/P, 8036 Graz, Austria

Full list of author information is available at the end of the article
} 
(Continued from previous page)

Trial registration: The study was approved by the local Bioethics Committee of Vienna, Austria (BMWF-66.010/0091-II/3b/2013).

Keywords: Diastolic dysfunction, Heart failure with preserved ejection fraction, Cardiovascular magnetic resonance, Dobutamine stress, Porcine model

\section{Background}

Heart failure with preserved ejection fraction (HFpEF) is a multifactorial heterogeneous clinical syndrome that is recognized as an independent risk factor for mortality and cardiovascular morbidity [1-3]. Mechanisms leading to symptomatic heart failure with preserved ejection fraction are incompletely understood, challenging the investigation of experimental models at risk to develop this syndrome [4]. Large animal models for HFpEF have been sparsely proposed and studied [5]. The deoxycorticosterone acetate (DOCA)-salt-induced hypertensive pig (hereafter, DOCA pig) has been introduced as a large animal model for mineralocorticoid-induced hypertension [6-8]. DOCA-salt-induced hypertension in the pig is associated with concentric left ventricular (LV) hypertrophy $[9,10]$, increased peripheral vascular resistance [11-14], and alterations in the contractile apparatus in vascular smooth muscle cells $[15,16]$. Recently Schwarzl at al. [17] documented left atrial (LA) dilatation, normal LV end-diastolic pressure at rest, but leftward shifted end-diastolic pressure-volume relationship, myocyte hypertrophy, titin isoform shift, reduced totaltitin phosphorylation in the sub-endocardial layer, and increased LV end-diastolic pressures at lower cardiac output during maximum simulated exercise in DOCA pigs. The authors concluded that this model of hypertensive heart disease mimics the cardiac phenotype of early-stage HFpEF $[17,18]$. Imaging parameters of ventricular, atrial and myocardial structure and function were, however, not characterized for this large animal model [17].

Cardiovascular magnetic resonance (CMR) is the standard of reference for non-invasive assessment of cardiac and myocardial function and morphology [19-22]. Employing CMR techniques such as cine imaging, myocardial tagging and 4D flow imaging at rest and during stress as well as myocardial T1 mapping should make it possible to investigate cardiac and myocardial function, evaluate stress-induced differences in cardiac or myocardial function and performance, and identify myocardial tissue alterations in a single investigation in DOCA pigs.

The aim of our explorative study was to evaluate comprehensive CMR imaging of DOCA pigs and weightmatched control pigs at rest and during dobutamine stress to characterize ventricular, atrial and myocardial structure and function of this phenotype model of early- stage HFpEF, and to identify potential non-invasive imaging markers of the disease.

\section{Methods}

The explorative study was approved by the local Bioethics Committee of Vienna, Austria (BMWF-66.010/0091-II/ $3 \mathrm{~b} / 2013$ ) and conformed to the guide for the care and use of laboratory animals, US National Institute of Health (NIH Publication No. 85-23, revised 1996). Thirteen female landrace pigs were enrolled. Arterial hypertension was induced in six animals by subcutaneous implantation of DOCA pellets $(100 \mathrm{mg} / \mathrm{kg}$, 90-day release, Innovative Research of America, USA) in combination with a highsalt, high-sugar, high- potassium diet. After 12 weeks of treatment, animals were examined by CMR imaging at rest and during dobutamine stress. One DOCA pig was excluded from analysis because of heart rate and blood pressure instability during the measurements, which could be attributed to florid pericarditis when attempting to acquire histologic samples. Seven weightmatched healthy animals served as controls. The characteristics of the DOCA and the control animals are summarized in Table 1.

\section{Experimental preparation}

Animals were sedated by intramuscular administration of ketamine $\left(20 \mathrm{mg} \cdot \mathrm{kg}^{-1}\right)$, midazolam $\left(0.25 \mathrm{mg} \cdot \mathrm{kg}^{-1}\right)$ and azaperone $\left(5 \mathrm{mg} \cdot \mathrm{kg}^{-1}\right)$. Anesthesia was induced by 30-60 mg propofol (Propofol "Fresenius" $1 \%$-Emulsion, Fresenius Kabi, Austria) to allow endotracheal intubation. Pigs were mechanically ventilated (Titus, Dräger Medical, Germany) and anesthesia was maintained with sevoflurane (1.5-2.5\%), fentanyl $\left(35 \mu \mathrm{g} \cdot \mathrm{kg}^{-1} \cdot \mathrm{h}^{-1}\right)$, midazolam $\left(1.2 \mathrm{mg} \cdot \mathrm{kg}^{-1} \cdot \mathrm{h}^{-1}\right)$, ketamine $\left(2-8 \mathrm{mg} \cdot \mathrm{kg}^{-1} \cdot \mathrm{h}^{-1}\right)$ and pancuronium $\left(0.2 \mathrm{mg} \cdot \mathrm{kg}^{-1} \cdot \mathrm{h}^{-1}\right)$. Respiratory gases (PM 8050 MRI, Dräger Medical, Germany), heart rate and arterial blood pressure (Precess 3160, InVivo, FL, US) were continuously monitored. Sheath accesses of the left internal carotid artery and jugular vein were surgically prepared. Blood samples collected from the arterial line were used to control oximetric and metabolic parameters (ABL700, Radiometer Medical ApS, Denmark). A balanced crystalloid infusion (Elo-Mel Isoton, Fresius Kabi, Austria) was administered at a fixed rate of $10 \mathrm{ml} \cdot \mathrm{kg}^{-1} \cdot \mathrm{h}^{-1}$ throughout the protocol. Oral temperature of animals was assessed by a sublingual thermometer and was maintained at 
Table 1 Characteristics of control and DOCA animals

\begin{tabular}{|c|c|c|c|c|c|c|c|c|}
\hline \multirow[b]{2}{*}{ Parameter } & \multicolumn{3}{|c|}{ Controls $(n=7)$} & \multicolumn{3}{|c|}{ DOCA $(n=5)$} & \multicolumn{2}{|c|}{ Controls vs. DOCA } \\
\hline & Rest & Stress & $p$ & Rest & Stress & $p$ & Prest & $p_{\text {stress }}$ \\
\hline weight (kg) & $58 \pm 9$ & & & $65 \pm 2$ & & & 0.090 & \\
\hline $\mathrm{BSA}\left(\mathrm{m}^{2}\right)$ & $1.05 \pm 0.10$ & & & $1.14 \pm 0.03$ & & & 0.085 & \\
\hline $\mathrm{Htc}(\%)$ & $28 \pm 2$ & & & $28 \pm 2$ & & & 0.796 & \\
\hline $\mathrm{DB}\left(\mu \mathrm{g} \cdot \mathrm{kg}^{-1} \cdot \mathrm{min}^{-1}\right)$ & & $2.7 \pm 0.7$ & & & $3.8 \pm 1.0$ & & & 0.045 \\
\hline $\mathrm{HR}\left(\mathrm{min}^{-1}\right)$ & $89 \pm 5$ & $114 \pm 3$ & $<0.001$ & $86 \pm 8$ & $110 \pm 13$ & 0.014 & 0.424 & 0.488 \\
\hline mBP $(\mathrm{mmHg})$ & $87 \pm 7$ & $95 \pm 13$ & 0.061 & $106 \pm 8$ & $101 \pm 12$ & 0.538 & 0.001 & 0.400 \\
\hline sBP (mmHg) & $103 \pm 8$ & $116 \pm 9$ & 0.004 & $125 \pm 6$ & $120 \pm 11$ & 0.536 & $<0.001$ & 0.493 \\
\hline $\mathrm{dBP}(\mathrm{mmHg})$ & $75 \pm 9$ & $82 \pm 16$ & 0.077 & $96 \pm 10$ & $86 \pm 12$ & 0.122 & 0.003 & 0.614 \\
\hline $\operatorname{RPP}\left(10^{2} \mathrm{mmHg} \cdot \mathrm{min}^{-1}\right)$ & $92 \pm 8$ & $132 \pm 11$ & $<0.001$ & $108 \pm 14$ & $132 \pm 17$ & 0.026 & 0.034 & 0.990 \\
\hline
\end{tabular}

$B S A$ body surface area, $H t c$ hematocrit, $D B$ dobutamine infusion rate, $H R$ heart rate, $m B P$ mean blood pressure, $s B P$ systolic blood pressure, $d B P$ diastolic blood pressure, $R P P(=s B P \times H R)$ rate-pressure product

$p$ is related to the rest-stress comparison within each group. $p_{\text {rest }}$ and $p_{\text {stress }}$ relate to group comparisons at rest and stress, respectively

$38{ }^{\circ} \mathrm{C}$ during $\mathrm{CMR}$ imaging via air ventilation and/or infusion of cold saline solution.

\section{Image acquisition}

CMR was performed on a $3 \mathrm{~T}$ MR scanner (Magnetom Trio, Siemens Healthcare, Germany) using a phasedarray 6-channel body matrix coil together with a spine matrix coil. Subjects were investigated in a single session during free breathing in the supine position with electrodes for electrocardiographic (ECG) gating positioned on the chest. After assessment of cardiac and myocardial function, blood flow and LV T1 times at rest, measurements were repeated during stress, which was induced by intravenous infusion of dobutamine (ERWO Pharma, Austria) at rates of $2-5 \mu \mathrm{g} \cdot \mathrm{kg}^{-1} \cdot \mathrm{min}^{-1}$, targeting a heart rate increase of approximately $25 \%$.

For assessment of ventricular and atrial function, retrospectively ECG-gated, 2D segmented fast low-angle shot (FLASH) cine images (temporal resolution, $27 \mathrm{~ms}$ interpolated to 40 cardiac phases; echo time, $2.7 \mathrm{~ms}$; flip angle, $15^{\circ}-20^{\circ}$; voxel size, $1.9 \times 1.6 \times 6.0-8.0 \mathrm{~mm}^{3}$ ) were obtained in the LV two-chamber, three- and fourchamber views (Fig. 1), and in contiguous short-axis slices covering the entire LV in 12-14 slices. Two-fold averaging was used to suppress breathing artefacts.

Aortic cross section, vessel wall thickness, and aortic peak blood velocity were evaluated on retrospectively ECG-gated, two-dimensional spoiled gradient-echobased through-plane velocity encoded cine phasecontrast images (velocity encoding, $110-200 \mathrm{~cm} \cdot \mathrm{s}^{-1}$; temporal resolution, $30 \mathrm{~ms}$ interpolated to 40 cardiac phases; echo time, $2.5 \mathrm{~ms}$; flip angle, $18^{\circ}$; voxel size, $1.8 \times 1.6 \times 6.0 \mathrm{~mm}^{3}$; 2-fold averaging) with image orientation adjusted perpendicular to the course of the proximal ascending aorta $2 \mathrm{~cm}$ above the aortic valve. Time-resolved three-directional phase-contrast imaging (4D flow) data were acquired to measure mitral annular tissue velocity and blood flow in the left heart, the pulmonary veins and the coronary sinus; the structures were covered by gapless slices with a retrospectively ECG-gated, two-dimensional spoiled gradient-echobased three-directional velocity-encoded cine phasecontrast sequence (velocity encoding in all directions, $110 \mathrm{~cm} \cdot \mathrm{s}^{-1}$; measured temporal resolution, $46 \mathrm{~ms}$ interpolated to 25 cardiac phases per cardiac cycle; echo time, $2.9 \mathrm{~ms}$; flip angle, $15^{\circ}$; voxel size, $2.5 \times 1.8 \times$ $4.0 \mathrm{~mm}^{3}$; 3-fold averaging).

To study myocardial strain, tagged cine images (Fig. 2) were acquired with a retrospectively ECG-gated FLASH with spatial modulation of magnetization (SPAMM) in the short axis (basal, mid-ventricular and apical) and in the 4-chamber orientation (grid spacing, $6 \mathrm{~mm}$; temporal resolution, $20 \mathrm{~ms}$ interpolated to 50 cardiac phases; echo time, $3.3 \mathrm{~ms}$; flip angle, $12^{\circ}$; voxel size, $1.8 \times 1.3 \times 6.0-8.0 \mathrm{~mm}^{3}$; 3-fold averaging).

An ECG-gated modified Look-Locker inversion recovery (MOLLI) prototype sequence with single-shot balanced steady-state free precession (bSSFP) readout, motion correction and automatic T1 map generation (MOLLI protocol 5(5)5(5)5; echo spacing, $2.6 \mathrm{~ms}$; echo time, $1.1 \mathrm{~ms}$; flip angle, $35^{\circ}$; voxel size, $2.1 \times 1.4 \times$ $8.0 \mathrm{~mm}^{3}$ ) was used to acquire myocardial $\mathrm{T} 1$ maps in end-diastole (Fig. 3).

\section{Left ventricular and myocardial function}

Short-axis cine images were analyzed by syngo.via software (MR Cardiac Function, Siemens Healthcare, Erlangen, Germany). To assess LV volume vs. time curves, LV epicardial and endocardial borders, excluding papillary muscles from myocardium, were traced manually in end-diastole and end-systole and semi-automatically adjusted to all cardiac phases (Fig. 1). To define the basal plane, the position of the mitral valve was evaluated from the cine four-chamber view. 


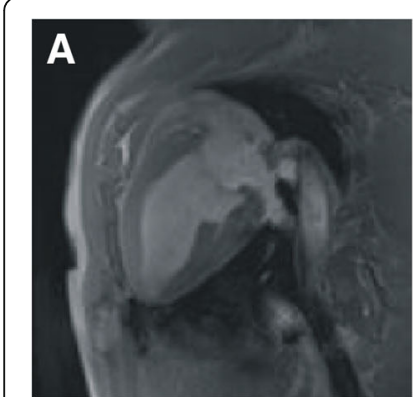

LV 2-chamber view

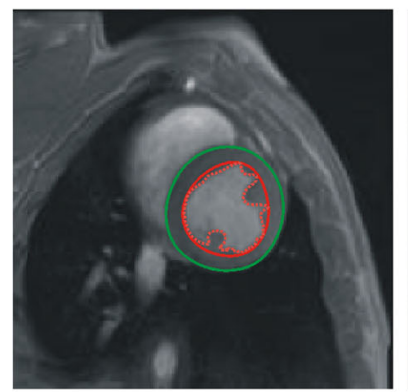

short axis view

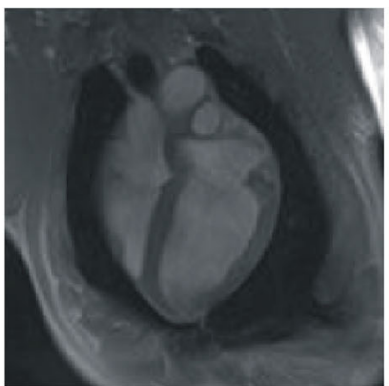

4-chamber view

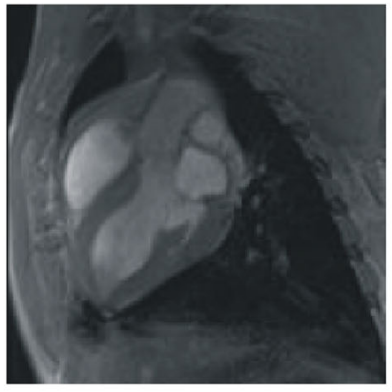

3-chamber view
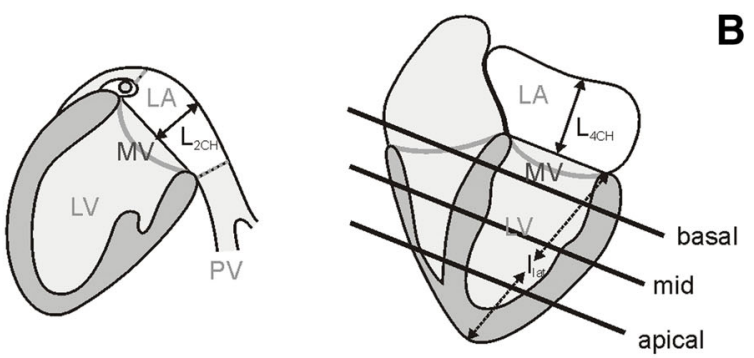

B

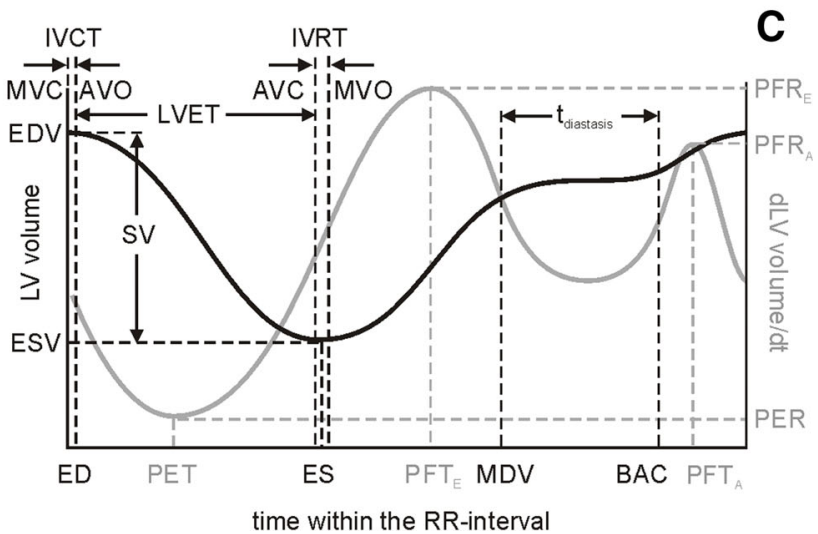

Fig. 1 Functional cine images and their evaluation. a Diastolic images of cine FLASH series in LV 2-chamber, 4-chamber, 3-chamber and mid-ventricular short-axis views. Subepicardial (green line) and subendocardial (red line) contouring in short axis images was employed to derive LV volume vs. time curves, wall thickness and left ventricular muscle mass (red dashed line). b Schematic drawing explaining derivation of left atrial volumes and mitral annular plane systolic excursion (MAPSE). $L V=$ left ventricle; $L A=$ left atrium area (white plane); $M V=$ mitral valve; $P V=$ pulmonary vein; $L_{4 C H}, L_{2} C H=$ length of $L A$ extension in 4-chamber view and 2-chamber view, respectively; $l_{\text {lat }}=$ distance from the apex to the lateral mitral annulus. $\mathbf{c}$ LV volume vs. time curve (black line) and its derivative (gray line). ED = time of LV end-diastole; ES = time of LV end-systole; MDV = mid-diastolic time after rapid LV filling; BAC = time before atrial contraction; $E D V=L V$ end-diastolic volume; ESV = LV end-systolic volume; $S V=L V$ stroke volume; $t_{\text {diastasis }}=$ duration of LV diastasis; PER = peak ejection rate; $P E T=$ peak ejection time; $P F R_{E}=$ early diastolic peak filling rate; $P F T_{E}=$ early diastolic peak filling time; $P F R_{A}=$ late diastolic peak filling rate; $\mathrm{PFT}_{\mathrm{A}}$ = late diastolic peak filling time. Times of aortic valve closure (AVC), aortic valve opening (AVO), mitral valve closure (MVC), and mitral valve opening (MVO) were assessed from cine 3-chamber view series. IVRT = isovolumetric relaxation time; IVCR = isovolumetric contraction time; LVET = left ventricular ejection time

Normalized end-diastolic volume (EDV), end-systolic volume (ESV), stroke volume, cardiac output, and LV ejection fraction were evaluated from end-diastolic and end-systolic cardiac phases with the body surface area (BSA) estimated according to BSA $\left(\mathrm{m}^{2}\right)=0.0734 \times$ weight $(\mathrm{kg})^{0.656}$ [23]. The duration of LV diastasis ( $t_{\text {diastasis }}$ ) was derived from LV volume vs. time curves as the time interval starting after rapid LV filling and atrial contraction. Derivative of LV volume-time curves provided assessment of normalized peak ejection rate (PER), peak ejection time (PET), as well as early $\left(\mathrm{PFR}_{\mathrm{E}}, \mathrm{PFT}_{\mathrm{E}}\right)$ and active $\left(\mathrm{PFR}_{\mathrm{A}}\right.$, $\mathrm{PFT}_{\mathrm{A}}$ ) normalized peak filling rates and times (Fig. 1).

Papillary muscles were included when measuring normalized left ventricular mass (LVMM), but they were excluded in determining normalized mean end-diastolic and end-systolic wall thickness and thickening at the basal, mid-myocardial and apical levels; 16 myocardial segments were evaluated, according to the American Heart Association (AHA) segmentation scheme [24]. Global normalized end-diastolic $\left(\mathrm{WT}_{\mathrm{ED}}\right)$ and end-systolic
$\left(\mathrm{WT}_{\mathrm{ES}}\right)$ wall thickness, as well as $\mathrm{LV}$ wall thickening, were calculated as averages of segmental values.

Times of mitral valve opening (MVO), mitral valve closure (MVC), and aortic valve opening (AVO)/closure (AVC) were derived from cine 3-chamber images by visual analysis (Fig. 1); in turn, these measurements were used to assess LV isovolumetric contraction $(\mathrm{IVCT}=\mathrm{AVO}-\mathrm{MVC})$, isovolumetric relaxation (IVRT = MVO-AVC) and ejection (LVET = AVC-AVO) times. Index of myocardial performance (IMP) was calculated from IMP $=($ IVCT + IVRT $) /$ LVET [25].

Mitral annular plane systolic excursion (MAPSE) was measured as the difference between the end-diastolic and the end-systolic distance from apex to lateral mitral annulus in 4-chamber view (Fig. 1).

\section{Left atrial volumes}

Left atrial (LA) volumes were evaluated from manually tracing the LA area and length in 4- and 2-chamber views (Fig. 1). Normalized LA volumes were determined 


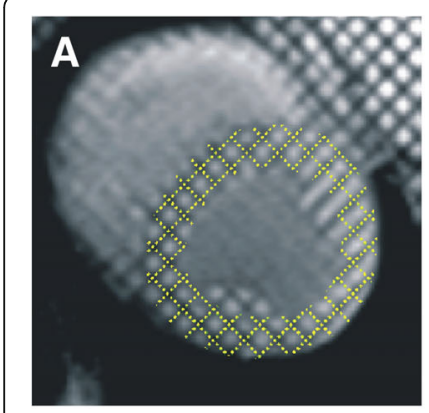

end-diastole

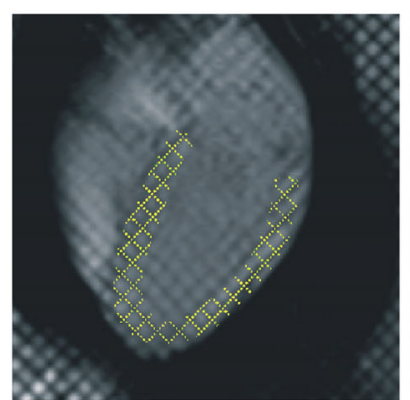

end-diastole

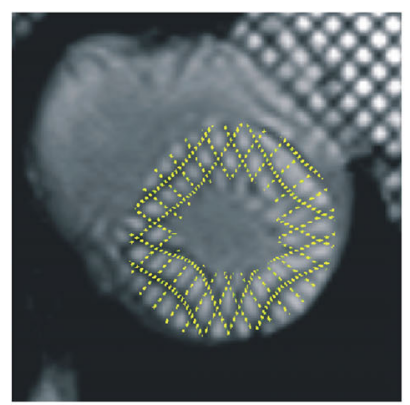

end-systole

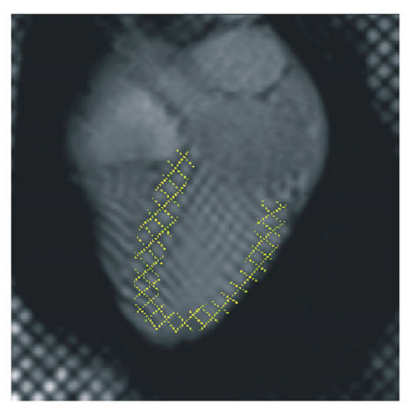

end-systole

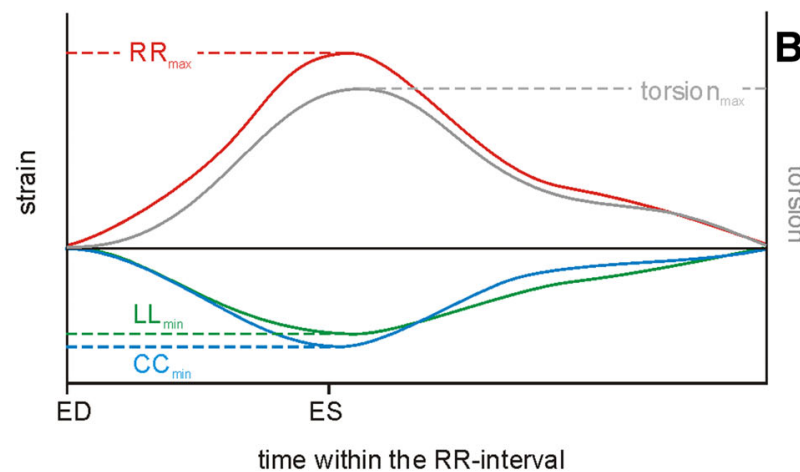

B

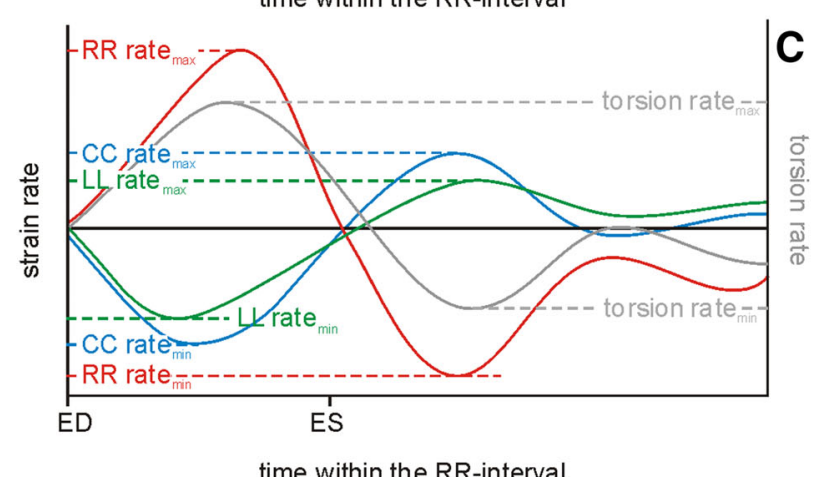

Fig. 2 Cine tagged images and their evaluation. a End-diastolic and end-systolic images of cine tagging series in mid-ventricular short-axis and 4-chamber orientations. Yellow grid lines detected by the evaluation software are overlaid. b Derived time courses of LV myocardial radial (RR, red line), circumferential (CC, blue line) and longitudinal ( $L \mathrm{~L}$, green line) strains and of LV myocardial torsion (gray line). Extrema of curves are annotated. c Derived time courses of LV myocardial radial (RR, red line), circumferential (CC, blue line) and longitudinal (LL, green line) strain rates and of LV myocardial torsion rate (gray line). Systolic and early diastolic extrema of curves are annotated. ED = time of LV end-diastole; ES $=$ time of LV end-systole

from cardiac phases before mitral valve opening at LV end-systole (maximum volume $\mathrm{LAV}_{\max }$ ) and before mitral valve closure after LA contraction (minimum volume $\left.\mathrm{LAV}_{\text {min }}\right)$. For consistency, the plane of the mitral annulus was defined as the LA inferior border. Areas of recesses of the mitral valve, pulmonary veins and left atrial appendage were excluded by drawing a straight line across these structures to adjacent atrial borders. LA length was measured from the center of the mitral plane to the superior margin of the LA in 4- and 2chamber views. Normalized LA volumes were estimated using the bi-planar area-length method [26] from LAV = $0.85 \times \mathrm{A}_{2 \mathrm{CH}} \times \mathrm{A}_{4 \mathrm{CH}} /(\mathrm{L} \times \mathrm{BSA})$, where $\mathrm{A}_{2 \mathrm{CH}}$ and $\mathrm{A}_{4 \mathrm{CH}}$ are the LA areas in 2-chamber and 4-chamber views, respectively, and $\mathrm{L}$ is the length of the LA from either the 2or the 4-chamber view (whichever is shorter). LA total ejection fraction (LATEF) was calculated according to $\mathrm{LATEF}=100 \times\left(\mathrm{LAV}_{\text {max }}-\mathrm{LAV}_{\text {min }}\right) / \mathrm{LAV}_{\max }$.

\section{Phase-contrast imaging data evaluation}

Aortic peak velocity and cross-sectional area were evaluated from through-plane phase-contrast images by syngo.via (MR Flow Analysis, Siemens Healthcare, Erlangen, Germany). Aortic vessel wall thickness (AWT) was assessed from aortic cross section diameter measured from outer and inner vessel borders at the cardiac phases with maximum vessel cross section area at rest according to $\mathrm{AWT}=$ (outer diameter - inner diameter $) / 2$.

Transmitral early (E) and late (A) diastolic, pulmonary venous systolic (S1, S2) and early diastolic (D) velocities, coronary sinus net forward blood flow volume (Fig. 4), and early diastolic lateral, septal and mean (E') mitral annular tissue velocities were evaluated from multiplanar images reconstructed from 4D flow data using prototype software (4D Flow, Siemens Healthcare, Erlangen, Germany). Transmitral acceleration (AT) and deceleration (DT) times were assessed from average mitral velocity vs. time curves. E/A, E/E', (E/E')/ EDV, and pulmonary venous $S / D$ (with $S$ as maximum of S1 and S2) ratios were calculated from peak through-plane velocities.

\section{Evaluation of global myocardial perfusion and perfusion reserve}

Global myocardial perfusion (GMP) was derived as quotient of coronary sinus net forward blood flow volume multiplied by heart rate (which represents the time-averaged coronary sinus blood flow) and the left 


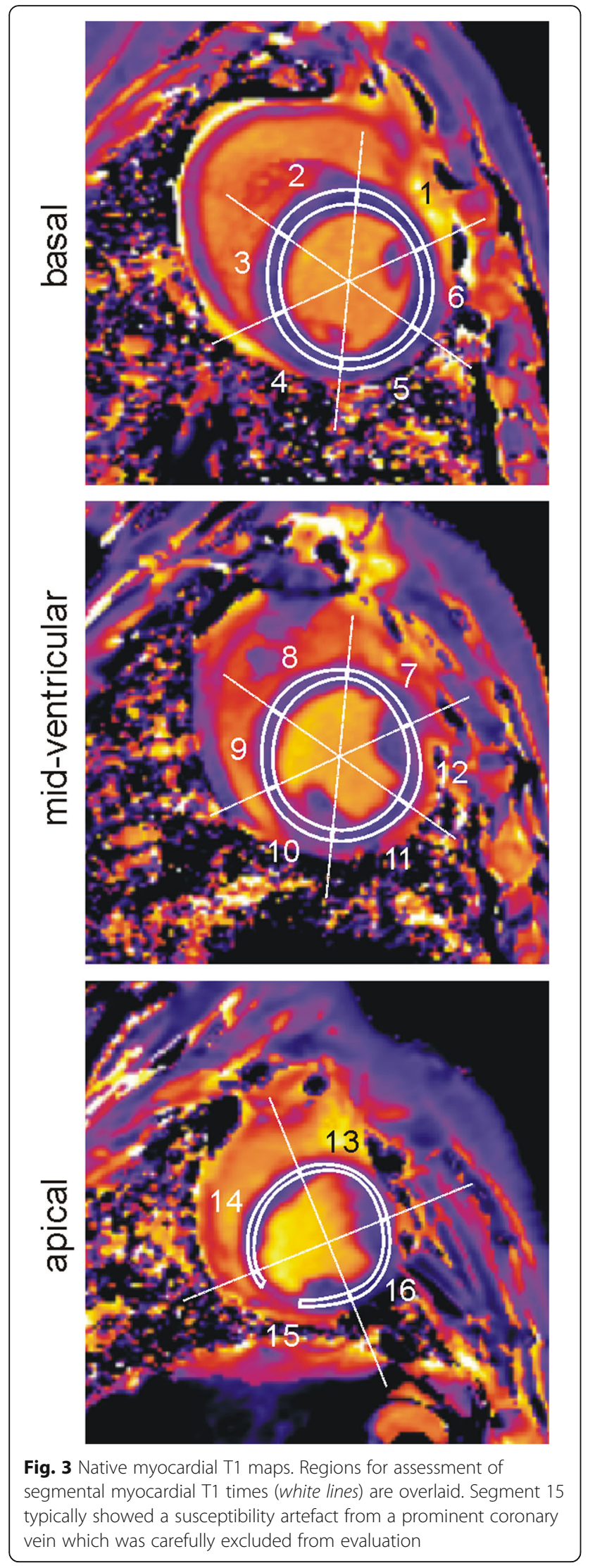

ventricular muscle mass [27]. Myocardial perfusion reserve (MPR) was calculated from stress-to-rest GMP [27].

\section{Evaluation of myocardial strain}

Tagged images were evaluated semi-automatically by using prototype software (Heart Deformation Analysis 2.0, Siemens Healthcare, Erlangen, Germany and University of Auckland). A grid was aligned to the myocardial tags at end-diastole and propagated throughout all images of the cardiac cycle (Fig. 2). Grids were manually corrected to the tags if necessary. Myocardial circumferential (CC) and radial strain (RR) and strain rates (CC rate, $R R$ rate) were calculated by the software from the motion of grid lines at the basal, mid-ventricular and apical levels from the respective short axis slices. Longitudinal myocardial strain (LL) and strain rates (LL rate) were assessed from 4-chamber view images, while myocardial torsion and torsion rates were assessed from the strains of basal and apical short-axis slices (Fig. 2). From time courses of strains, torsion and corresponding rates, end-systolic maxima/minima of strains and torsion as well as systolic and early diastolic maxima/minima of rates were determined. Furthermore, LV circumferential and radial strains and strain rates were calculated as means of basal, mid-ventricular and apical values.

\section{Evaluation of native myocardial $\mathrm{T} 1$ times}

Segmental LV myocardial T1 times were derived by manually outlining T1 maps according to the AHA segmentation scheme, excluding blood pool, papillary muscles, trabeculae and epicardial structures. Regions were drawn to be as large as possible while avoiding inclusion of subendocardial and subepicardial tissue boundaries (Fig. 3). Global LV myocardial T1 was calculated as mean of segmental values.

\section{Electron microscopy and stereology}

After in vivo measurements were completed, thoracotomy was performed and a bolus of $100 \mathrm{mmol}$ potassium was administered intracoronarily to sacrifice each animal. For electron microscopic analysis of the myocardium, transmural biopsies were then collected from the lateral left ventricular wall and fixed in $1.5 \%$ glutaraldehyde, $1.5 \%$ paraformaldehyde in $0.15 \mathrm{M}$ Hepes buffer. The samples were then stored in the fixative at $4{ }^{\circ} \mathrm{C}$ until further processing. The processing steps included postfixation in $1 \%$ osmium tetroxide solution, overnight staining in half-saturated uranyl acetate solution, dehydration in an ascending acetone series and finally embedding in epoxy resin. From the embedded samples, semi- and ultrathin sections were obtained for stereological analysis. The following parameters were assessed by the method of point counting [28]: volume fraction of 

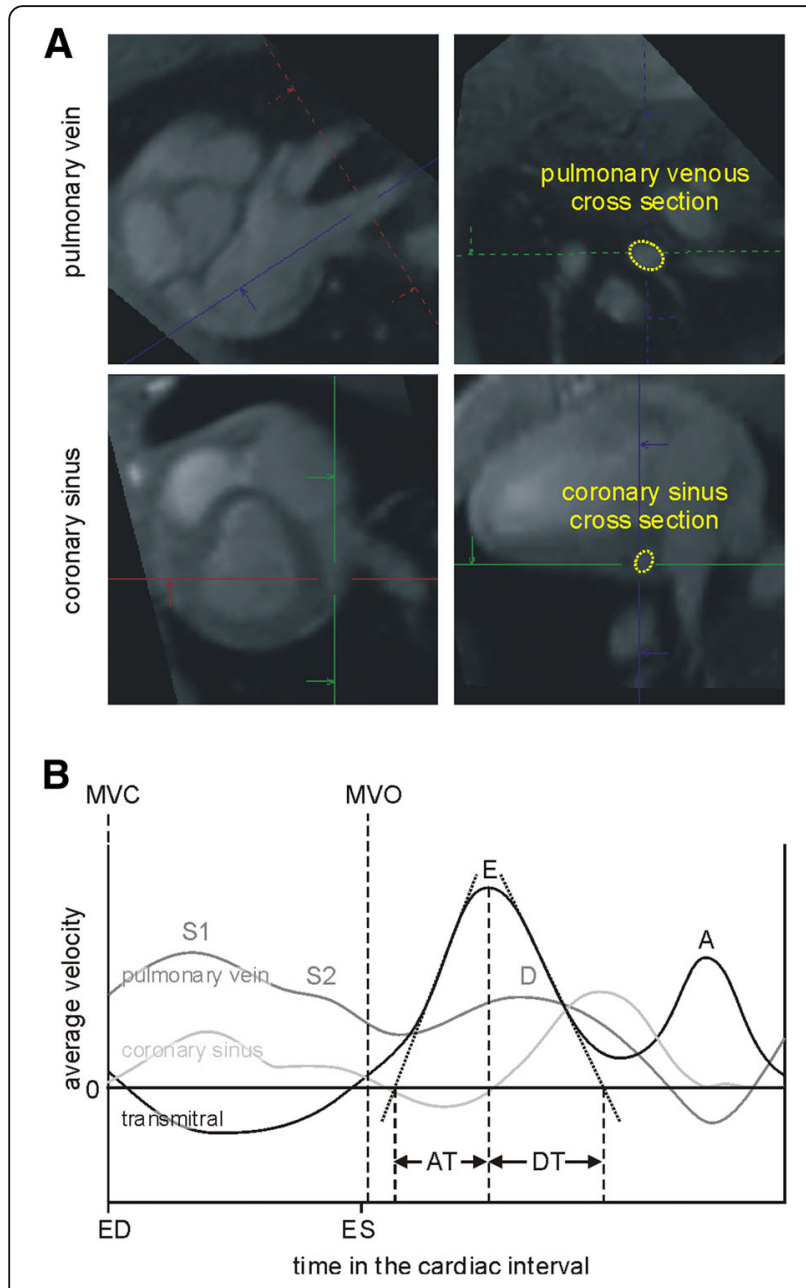

Fig. 4 Evaluation of mitral, pulmonary venous and coronary sinus blood flow parameters from 4D flow data. a Cross-sectional areas were defined in multi-planar reformatted image planes of the anatomical phase-contrast data. The definition of pulmonary venous and coronary sinus cross sections are displayed. b Derived transmitral (black line), pulmonary venous (gray line), and coronary sinus (light gray line) average velocity vs. time courses. Peak through-plane velocities of transmitral early (E) and late (A) diastolic, pulmonary venous systolic $(\mathrm{S} 1, \mathrm{~S} 2)$ and early diastolic (D) were evaluated from respective peak velocity vs. time curves. E-wave acceleration (AT) and deceleration (DT) times were estimated by linear approximation of the acceleration and deceleration phase of the early diastolic transmitral average velocities. Coronary sinus net forwards blood volume was assessed from integration of average velocity $\times$ cross-sectional area. $E D=$ time of $\mathrm{LV}$ end-diastole; $\mathrm{ES}=$ time of $\mathrm{LV}$ end-systole; MVC = time of mitral valve closure; $\mathrm{MVO}=$ time of mitral valve opening

interstitium $\left(\mathrm{V}_{\mathrm{V}}(\mathrm{int} / \mathrm{lv})\right)$, volume fraction of cardiomyocytes $\left(\mathrm{V}_{\mathrm{V}}(\mathrm{myo}, \mathrm{lv})=1-\mathrm{V}_{\mathrm{V}}(\mathrm{int} / \mathrm{lv})\right)$, of blood vessels $\left(\mathrm{V}_{\mathrm{V}}(\mathrm{ves} / \mathrm{lv})\right)$ and of collagen fibrils either related to the left ventricle $\left(\mathrm{V}_{\mathrm{V}}(\mathrm{coll} / \mathrm{lv})\right)$ or to the interstitium $\left(\mathrm{V}_{\mathrm{V}}(\mathrm{coll} /\right.$ int)) as reference volume. The total myocyte $(\mathrm{V}(\mathrm{myo}, \mathrm{lv}))$, collagen V(coll,lv) and blood vessel V(ves,lv) content in the myocardium were obtained by multiplying LVMM with $\mathrm{V}_{\mathrm{V}}(\mathrm{myo} / \mathrm{lv}), \mathrm{V}_{\mathrm{V}}(\mathrm{coll} / \mathrm{lv})$, and $\mathrm{V}_{\mathrm{V}}(\mathrm{ves} / \mathrm{lv})$, respectively.

\section{Statistical analysis}

Mean values are given together with standard deviations. Statistical analysis was performed using NCSS (Hintze, J. (2008) NCSS, LLC. Kaysville, Utah). A significance level of 0.05 was employed for statistical tests. Rest and stress indices of left heart and myocardial function as well as morphological and stereological parameters assessed in DOCA and control animals were compared by 2-sample $t$-test. Significances of differences of rest and stress indices or absolute and relative stress reserves were tested by 1 -sample $t$-test.

\section{Results}

DOCA pigs developed hypertension within 12 weeks. At rest, arterial blood pressure (mean, systolic and diastolic) and the rate-pressure product were higher in DOCA pigs than in controls; the groups did not differ significantly in weight, BSA and heart rate (Table 1). A stress-induced heart rate increase of $25 \%$ was reached at significantly higher infusion rates in DOCA subjects (controls, $2.7 \pm 0.7 \mu \mathrm{g} \cdot \mathrm{kg}^{-1} \cdot \mathrm{min}^{-1}$; DOCA, $3.8 \pm 1.0 \mu \mathrm{g}$. $\left.\mathrm{kg}^{-1} \cdot \mathrm{min}^{-1}\right)$. During stress, blood pressure in DOCA subjects failed to increase, and thus differences in blood pressures and rate-pressure product disappeared between groups.

\section{Left ventricular and myocardial function, left atrial volumetry} LVMM was higher in DOCA than in control animals (Table 2). DOCA animals revealed concentric hypertrophy with increased $\mathrm{WT}_{\mathrm{ED}}$ and $\mathrm{WT}_{\mathrm{ES}}$ at rest and during stress. LV wall thickening and MAPSE were different between groups at rest but not during stress.

Stress-induced changes of systolic LV function indices were comparable for DOCA and control animals except for the increase in cardiac index, which was lower in DOCA animals (controls, $63 \pm 23 \%$; DOCA, $37 \pm 12 \%$; $p=0.040)$ and the decrease in EDV, which was higher in DOCA animals (controls, $-5 \pm 11 \%$; DOCA, $-20 \pm 11 \%$; $p=0.043$ ). IVRT was longer in DOCA at rest but did not differ significantly between groups during stress (Table 3).

Minimal and maximal LA volumes were enlarged in DOCA animals at rest. As maximal LA volume in the DOCA group significantly decreased during stress, LATEF, which was comparable between groups at rest, was significantly smaller in the DOCA group during stress (Table 2).

\section{Phase-contrast velocity mapping}

Aortic wall was thicker in DOCA pigs (Table 4). Aortic blood peak velocity was higher in controls than in DOCA animals at rest but equalized during stress. At rest, the minimal, maximal and average aortic crosssectional areas were larger in DOCA than in control 
Table 2 Parameters of cardiac and myocardial geometry and function

\begin{tabular}{|c|c|c|c|c|c|c|c|c|}
\hline \multirow[b]{2}{*}{ Parameter } & \multicolumn{3}{|c|}{ Controls $(n=7)$} & \multicolumn{3}{|c|}{ DOCA $(n=5)$} & \multicolumn{2}{|c|}{ Controls vs. DOCA } \\
\hline & Rest & Stress & p & Rest & Stress & $p$ & Prest & $p_{\text {stress }}$ \\
\hline $\operatorname{LVMM}\left(\mathrm{g} \cdot \mathrm{m}^{-2}\right)$ & $84 \pm 7$ & & & $111 \pm 9$ & & & $<0.001$ & \\
\hline$W T_{E D}\left(m m \cdot m^{-2}\right)$ & $6.3 \pm 1.2$ & $6.2 \pm 1.4$ & 0.934 & $8.3 \pm 0.8$ & $9.3 \pm 1.6$ & 0.224 & 0.007 & 0.006 \\
\hline$W T_{E S}\left(m m \cdot m^{-2}\right)$ & $9.6 \pm 1.6$ & $11.8 \pm 2.2$ & 0.009 & $13.0 \pm 1.4$ & $15.5 \pm 1.9$ & 0.012 & 0.003 & 0.012 \\
\hline $\mathrm{WTH}\left(\mathrm{mm} \cdot \mathrm{m}^{-2}\right)$ & $3.3 \pm 0.8$ & $5.6 \pm 1.7$ & 0.019 & $4.8 \pm 0.9$ & $6.2 \pm 1.1$ & 0.074 & 0.020 & 0.489 \\
\hline MAPSE (mm) & $11.1 \pm 3.6$ & $15.0 \pm 3.7$ & 0.078 & $6.9 \pm 1.2$ & $13.5 \pm 4.9$ & 0.040 & 0.037 & 0.586 \\
\hline EF (\%) & $52 \pm 3$ & $69 \pm 7$ & 0.001 & $53 \pm 5$ & $70 \pm 2$ & $<0.001$ & 0.840 & 0.749 \\
\hline $\operatorname{EDV}\left(\mathrm{ml} \cdot \mathrm{m}^{-2}\right)$ & $124 \pm 15$ & $117 \pm 12$ & 0.293 & $125 \pm 18$ & $102 \pm 26$ & 0.008 & 0.862 & 0.203 \\
\hline $\operatorname{ESV}\left(\mathrm{ml} \cdot \mathrm{m}^{-2}\right)$ & $59 \pm 9$ & $36 \pm 10$ & 0.005 & $59 \pm 10$ & $30 \pm 9$ & $<0.001$ & 0.983 & 0.360 \\
\hline $\mathrm{SV}\left(\mathrm{ml} \cdot \mathrm{m}^{-2}\right)$ & $65 \pm 8$ & $81 \pm 9$ & 0.003 & $66 \pm 11$ & $71 \pm 17$ & 0.352 & 0.781 & 0.244 \\
\hline $\mathrm{Cl}\left(\mathrm{I} \mathrm{min}^{-1} \cdot \mathrm{m}^{-2}\right)$ & $5.8 \pm 0.9$ & $9.4 \pm 1.1$ & $<0.001$ & $5.8 \pm 1.0$ & $7.8 \pm 1.2$ & 0.002 & 0.890 & 0.041 \\
\hline $\operatorname{PER}\left(\mathrm{ml} \cdot \mathrm{s}^{-1} \cdot \mathrm{m}^{-2}\right)$ & $-380 \pm 54$ & $-711 \pm 219$ & 0.005 & $-419 \pm 95$ & $-639 \pm 114$ & 0.002 & 0.389 & 0.523 \\
\hline $\operatorname{PFR}_{E}\left(m l \cdot s^{-1} \cdot m^{-2}\right)$ & $307 \pm 41$ & $470 \pm 75$ & 0.002 & $332 \pm 69$ & $471 \pm 49$ & 0.007 & 0.449 & 0.979 \\
\hline $\mathrm{PFR}_{\mathrm{A}}\left(\mathrm{ml} \cdot \mathrm{s}^{-1} \cdot \mathrm{m}^{-2}\right)$ & $302 \pm 73$ & $345 \pm 99$ & 0.223 & $334 \pm 133$ & $277 \pm 118$ & 0.192 & 0.599 & 0.304 \\
\hline$L A V_{\max }\left(\mathrm{ml} \cdot \mathrm{m}^{-2}\right)$ & $34 \pm 4$ & $32 \pm 8$ & 0.444 & $48 \pm 17$ & $34 \pm 14$ & 0.012 & 0.042 & 0.798 \\
\hline$L A V_{\min }\left(\mathrm{ml} \cdot \mathrm{m}^{-2}\right)$ & $14 \pm 3$ & $14 \pm 4$ & 0.655 & $25 \pm 9$ & $21 \pm 8$ & 0.222 & 0.012 & 0.054 \\
\hline LATEF (\%) & $58 \pm 4$ & $58 \pm 11$ & 0.990 & $48 \pm 14$ & $36 \pm 10$ & 0.265 & 0.104 & 0.006 \\
\hline
\end{tabular}

LVMM left ventricular muscle mass, $W T_{E D}$ end-diastolic wall thickness, $W T_{E S}$ end-systolic wall thickness, $W T H$ wall thickening, MAPSE mitral annular plane systolic excursion, EF left ventricular ejection fraction, EDV left ventricular end-diastolic volume, ESV left ventricular end-systolic volume, SV left ventricular stroke volume, $C l$ left ventricular cardiac index, $P E R$ peak ejection rate, $P F R_{E}$ early diastolic peak filling rate, $P F R_{A}$ late diastolic peak filling rate, $L A V_{\text {max }}$ left atrial maximum volume, $L A V_{\text {min }}$ left atrial minimal volume, LATEF left atrial total ejection fraction

$p$ is related to the rest-stress comparison within each group. $p_{\text {rest }}$ and $p_{\text {stress }}$ relate to group comparisons at rest and stress, respectively

pigs; with stress, these differences became insignificant except for the difference in minimal aortic crosssectional area.

Early diastolic myocardial tissue peak velocity values were lower in DOCA pigs and corresponded to higher $\mathrm{E} / \mathrm{E}^{\prime}$ in the DOCA group, even though transmitral inflow patterns did not differ between groups (Table 4). $\left(\mathrm{E} / \mathrm{E}^{\prime}\right) / \mathrm{EDV}$ was higher in DOCA pigs both at rest and during stress.

The main differences in the pulmonary venous flow patterns between the two groups were that DOCA pigs showed significantly higher D-wave velocities at rest, while controls displayed a significant stress-induced increase in pulmonary venous peak velocities that was not observed in the DOCA group. Accordingly, the S/D ratio differed significantly between the two groups at rest but not during stress.

\section{Global myocardial perfusion and perfusion reserve}

Under rest coronary sinus net forward blood volume was larger in the DOCA pigs than in the control pigs, but equalized under stress condition. Although global

Table 3 Time intervals and indices of left ventricular function

\begin{tabular}{|c|c|c|c|c|c|c|c|c|}
\hline \multirow[b]{2}{*}{ Parameter } & \multicolumn{3}{|c|}{ Controls $(n=7)$} & \multicolumn{3}{|c|}{ DOCA $(n=5)$} & \multicolumn{2}{|c|}{ Controls vs. DOCA } \\
\hline & Rest & Stress & $p$ & Rest & Stress & $p$ & Prest & $p_{\text {stress }}$ \\
\hline PET (ms) & $82 \pm 24$ & $46 \pm 23$ & 0.006 & $110 \pm 19$ & $46 \pm 16$ & 0.007 & 0.053 & 0.972 \\
\hline $\mathrm{PFT}_{\mathrm{E}}(\mathrm{ms})$ & $382 \pm 35$ & $286 \pm 19$ & $<0.001$ & $389 \pm 37$ & $289 \pm 34$ & 0.001 & 0.752 & 0.831 \\
\hline $\mathrm{PFT}_{\mathrm{A}}$ (ms) & $586 \pm 36$ & $446 \pm 13$ & $<0.001$ & $622 \pm 66$ & $485 \pm 67$ & 0.007 & 0.255 & 0.160 \\
\hline IVRT (ms) & $80 \pm 15$ & $78 \pm 16$ & 0.786 & $99 \pm 10$ & $93 \pm 17$ & 0.618 & 0.034 & 0.146 \\
\hline IVCT (ms) & $46 \pm 14$ & $28 \pm 8$ & 0.013 & $56 \pm 9$ & $34 \pm 11$ & $<0.001$ & 0.175 & 0.330 \\
\hline LVET (ms) & $205 \pm 36$ & $141 \pm 22$ & 0.008 & $194 \pm 29$ & $129 \pm 53$ & 0.005 & 0.600 & 0.606 \\
\hline IMP & $0.64 \pm 0.23$ & $0.77 \pm 0.18$ & 0.353 & $0.82 \pm 0.17$ & $1.20 \pm 0.82$ & 0.313 & 0.179 & 0.201 \\
\hline $\mathrm{t}_{\text {diastase }}(\mathrm{ms})$ & $90 \pm 34$ & $55 \pm 28$ & 0.017 & $94 \pm 43$ & $67 \pm 14$ & 0.139 & 0.858 & 0.408 \\
\hline
\end{tabular}

PET peak ejection time, $P F T_{E}$ early diastolic peak filling time, $P F T_{A}$ late diastolic peak filling time, IVRT isovolumetric relaxation time, $I V C R$ isovolumetric contraction time, LVET left ventricular ejection time, IMP index of myocardial performance, $t_{\text {diastase }}$ duration of left ventricular diastasis

$p$ is related to the rest-stress comparison within each group. $p_{\text {rest }}$ and $p_{\text {stress }}$ relate to group comparisons at rest and stress, respectively 
Table 4 Phase-contrast velocity mapping-based parameters

\begin{tabular}{|c|c|c|c|c|c|c|c|c|}
\hline \multirow[b]{2}{*}{ Parameter } & \multicolumn{3}{|c|}{ Controls $(n=7)$} & \multicolumn{3}{|c|}{ DOCA $(n=5)$} & \multicolumn{2}{|c|}{ Controls vs. DOCA } \\
\hline & Rest & Stress & $p$ & Rest & Stress & p & Prest & $p_{\text {stress }}$ \\
\hline \multicolumn{9}{|c|}{ Aortic vessel wall and aortic blood velocity } \\
\hline $\operatorname{APV}\left(\mathrm{cm} \cdot \mathrm{s}^{-1}\right)$ & $113 \pm 15$ & $158 \pm 26$ & 0.001 & $92 \pm 14$ & $140 \pm 31$ & 0.011 & 0.033 & 0.308 \\
\hline$A A_{\text {mean }}\left(\mathrm{mm}^{-2}\right)$ & $3.4 \pm 0.4$ & $3.7 \pm 0.7$ & 0.091 & $5.5 \pm 0.5$ & $5.0 \pm 1.3$ & 0.244 & $<0.001$ & 0.064 \\
\hline$A A_{\min }\left(\mathrm{mm}^{-2}\right)$ & $2.8 \pm 0.4$ & $3.0 \pm 0.6$ & 0.211 & $4.6 \pm 0.5$ & $4.2 \pm 1.1$ & 0.229 & $<0.001$ & 0.044 \\
\hline$A A_{\max }\left(m^{-2}\right)$ & $4.1 \pm 0.4$ & $4.5 \pm 0.6$ & 0.061 & $6.3 \pm 0.5$ & $5.7 \pm 1.4$ & 0.228 & $<0.001$ & 0.072 \\
\hline AWT (mm) & $1.8 \pm 0.3$ & & & $2.3 \pm 0.4$ & & & 0.039 & \\
\hline \multicolumn{9}{|c|}{ Transmitral and myocardial tissue velocities } \\
\hline$E\left(\mathrm{~cm} \cdot \mathrm{s}^{-1}\right)$ & $63 \pm 6$ & $78 \pm 9$ & 0.001 & $56 \pm 10$ & $70 \pm 11$ & 0.001 & 0.181 & 0.222 \\
\hline $\mathrm{A}\left(\mathrm{cm} \cdot \mathrm{s}^{-1}\right)$ & $47 \pm 11$ & $48 \pm 9$ & 0.714 & $43 \pm 12$ & $43 \pm 13$ & 0.801 & 0.532 & 0.404 \\
\hline E/A & $1.4 \pm 0.5$ & $1.7 \pm 0.5$ & 0.100 & $1.4 \pm 0.4$ & $1.7 \pm 0.5$ & $<0.001$ & 0.861 & 0.886 \\
\hline AT (ms) & $87 \pm 17$ & $79 \pm 9$ & 0.329 & $83 \pm 14$ & $70 \pm 9$ & 0.091 & 0.639 & 0.120 \\
\hline DT (ms) & $152 \pm 50$ & $163 \pm 66$ & 0.705 & $169 \pm 67$ & $153 \pm 16$ & 0.639 & 0.622 & 0.760 \\
\hline$E_{s e p}^{\prime}\left(\mathrm{cm} \cdot \mathrm{s}^{-1}\right)$ & $18 \pm 4$ & $20 \pm 6$ & 0.743 & $11 \pm 3$ & $14 \pm 2$ & 0.109 & 0.010 & 0.069 \\
\hline $\mathrm{E}_{\text {lat }}^{\prime}\left(\mathrm{cm} \cdot \mathrm{s}^{-1}\right)$ & $21 \pm 5$ & $25 \pm 6$ & 0.346 & $14 \pm 3$ & $16 \pm 3$ & 0.213 & 0.067 & 0.019 \\
\hline $\mathrm{E}^{\prime}\left(\mathrm{cm} \cdot \mathrm{s}^{-1}\right)$ & $20 \pm 4$ & $23 \pm 6$ & 0.492 & $13 \pm 2$ & $15 \pm 2$ & 0.130 & 0.007 & 0.025 \\
\hline$E / E^{\prime}$ & $3.3 \pm 0.6$ & $3.6 \pm 0.7$ & 0.185 & $4.4 \pm 1.1$ & $4.6 \pm 0.6$ & 0.707 & 0.038 & 0.031 \\
\hline$\left(\mathrm{E}^{\prime} \mathrm{E}^{\prime}\right) / \mathrm{EDV}\left(10^{-2} \mathrm{ml}^{-1} \cdot \mathrm{m}^{2}\right)$ & $2.7 \pm 0.5$ & $3.1 \pm 0.6$ & 0.151 & $3.6 \pm 0.9$ & $4.8 \pm 1.6$ & 0.112 & 0.035 & 0.030 \\
\hline \multicolumn{9}{|l|}{ Pulmonary venous velocities } \\
\hline $\mathrm{S} 1\left(\mathrm{~cm} \cdot \mathrm{s}^{-1}\right)$ & $33 \pm 9$ & $48 \pm 4$ & 0.006 & $39 \pm 18$ & $46 \pm 5$ & 0.516 & 0.502 & 0.408 \\
\hline $\mathrm{S} 2\left(\mathrm{~cm} \cdot \mathrm{s}^{-1}\right)$ & $40 \pm 10$ & $49 \pm 9$ & 0.032 & $44 \pm 18$ & $44 \pm 5$ & 0.668 & 0.624 & 0.484 \\
\hline $\mathrm{D}\left(\mathrm{cm} \cdot \mathrm{s}^{-1}\right)$ & $37 \pm 10$ & $56 \pm 11$ & $<0.001$ & $57 \pm 17$ & $58 \pm 6$ & 0.792 & 0.035 & 0.636 \\
\hline$S / D$ & $1.1 \pm 0.2$ & $0.9 \pm 0.2$ & 0.019 & $0.8 \pm 0.2$ & $0.8 \pm 0.2$ & 0.864 & 0.045 & 0.194 \\
\hline \multicolumn{9}{|l|}{ Coronary sinus } \\
\hline $\mathrm{NFV}_{\mathrm{CS}}\left(\mathrm{ml} \cdot \mathrm{m}^{-2}\right)$ & $1.6 \pm 0.5$ & $2.7 \pm 1.0$ & 0.003 & $2.4 \pm 0.6$ & $2.8 \pm 0.5$ & 0.300 & 0.025 & 0.886 \\
\hline $\operatorname{GMP}\left(\mathrm{ml} \cdot \mathrm{min}^{-1} \cdot \mathrm{g}^{-1}\right)$ & $1.6 \pm 0.4$ & $3.7 \pm 1.4$ & 0.002 & $1.9 \pm 0.3$ & $2.9 \pm 0.5$ & 0.029 & 0.197 & 0.268 \\
\hline MPR & & $2.2 \pm 0.5$ & & & $1.5 \pm 0.4$ & & & 0.028 \\
\hline
\end{tabular}

$A P V$ aortic peak velocity, $A A_{\text {mean }}$ average aortic cross section area, $A A_{\min }$ minimal aortic cross section area, $A A_{\text {max }}$ maximal aortic cross section area, $A W T$ aortic wall thickness, $E$ early diastolic transmitral peak velocity, $A$ late diastolic transmitral peak velocity, $E_{\text {sept }}^{\prime}$ early diastolic septal wall mitral annular tissue velocity, $E_{\text {lat }}^{\prime}$ early diastolic lateral wall mitral annular tissue velocity, $E^{\prime}$ average early diastolic mitral annular tissue velocity, $S 1$ early systolic pulmonary venous peak velocity, $S 2$ systolic pulmonary venous peak velocity, $D$ early diastolic pulmonary venous peak velocity, $S$ maximal systolic pulmonary venous peak velocity, $N F V_{C S}$ coronary sinus net forward volume, GMP global myocardial perfusion, MPR stress-to-rest myocardial perfusion reserve

$p$ is related to the rest-stress comparison within each group. $p_{\text {rest }}$ and $p_{\text {stress }}$ relate to group comparisons at rest and stress, respectively

myocardial perfusion did not differ significantly between groups and increased with stress in both groups, myocardial perfusion reserve was significantly smaller in the DOCA group (Table 4).

\section{LV myocardial strains and torsion}

Circumferential, radial and longitudinal strains and strain rates as well as torsion and torsion rates were evaluated in all DOCA and 6 controls pigs. One control pig was excluded from evaluation due to poor tagged imaging quality.

Differences between DOCA and control pigs were found in the longitudinal strain and torsion rates (Table 5). Whereas systolic LL rate min $_{\text {in }}$ did not differ between groups at rest, it was smaller in DOCA animals

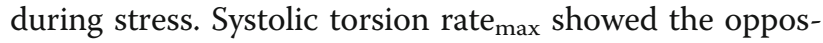
ite behavior, being significantly higher in DOCA pigs at rest but not during stress. Diastolic torsion rate min $_{\text {did }}$ differ significantly between groups; however, the torsion rate $_{\min }$ failed to properly increase during stress in the DOCA group (control, $-19 \pm 11^{\circ} \cdot \mathrm{s}^{-1}$; DOCA, $0 \pm 5^{\circ} \cdot \mathrm{s}^{-1}$; $p=0.015)$.

\section{Global LV myocardial T1 times}

Native myocardial T1 relaxation times were evaluated in 5 DOCA and 6 control animals. One control pig was excluded from evaluation due to poor image quality. No differences between groups were found in global native T1 times (controls, $1195 \pm 36 \mathrm{~ms}$; DOCA, $1161 \pm 21 \mathrm{~ms} ; p=0.094)$. 
Table 5 Left ventricular myocardial strain and torsion

\begin{tabular}{|c|c|c|c|c|c|c|c|c|}
\hline \multirow[b]{2}{*}{ Parameter } & \multicolumn{3}{|c|}{ Controls $(n=6)$} & \multicolumn{3}{|c|}{ DOCA $(n=5)$} & \multicolumn{2}{|c|}{ Controls vs. DOCA } \\
\hline & Rest & Stress & $p$ & Rest & Stress & $p$ & Prest & $p_{\text {stress }}$ \\
\hline$C C_{\min , L V}(\%)$ & $-16 \pm 1$ & $-17 \pm 2$ & 0.887 & $-17 \pm 2$ & $-18 \pm 3$ & 0.404 & 0.728 & 0.284 \\
\hline $\mathrm{RR}_{\max , \mathrm{LV}}(\%)$ & $34 \pm 12$ & $39 \pm 11$ & 0.163 & $33 \pm 4$ & $35 \pm 5$ & 0.533 & 0.764 & 0.481 \\
\hline$L L_{\min , L V}(\%)$ & $-13 \pm 2$ & $-13 \pm 3$ & 0.495 & $-12 \pm 1$ & $-11 \pm 2$ & 0.342 & 0.187 & 0.337 \\
\hline torsion $_{\max }\left({ }^{\circ}\right)$ & $4.6 \pm 1.4$ & $5.7 \pm 1.6$ & 0.560 & $6.1 \pm 0.9$ & $7.0 \pm 1.2$ & 0.061 & 0.098 & 0.231 \\
\hline CC rate $\min , L V_{\text {LV }}\left(\% \cdot \mathrm{s}^{-1}\right)$ & $-90 \pm 11$ & $-139 \pm 19$ & 0.009 & $-96 \pm 13$ & $-155 \pm 16$ & $<0.001$ & 0.436 & 0.182 \\
\hline RR rate max,$L V\left(\% \cdot \mathrm{s}^{-1}\right)$ & $185 \pm 52$ & $337 \pm 66$ & $<0.001$ & $188 \pm 36$ & $309 \pm 81$ & 0.015 & 0.908 & 0.540 \\
\hline LL rate $\min \left(\% \cdot s^{-1}\right)$ & $-77 \pm 11$ & $-120 \pm 15$ & 0.002 & $-68 \pm 6$ & $-95 \pm 13$ & 0.004 & 0.120 & 0.024 \\
\hline torsion rate $\max \left({ }^{\circ} \cdot \mathrm{s}^{-1}\right)$ & $29 \pm 3$ & $47 \pm 15$ & 0.044 & $44 \pm 8$ & $62 \pm 17$ & 0.103 & 0.002 & 0.193 \\
\hline CC rate $_{\max , L \mathrm{~V}}\left(\% \cdot \mathrm{s}^{-1}\right)$ & $83 \pm 4$ & $119 \pm 30$ & 0.023 & $89 \pm 11$ & $129 \pm 20$ & 0.005 & 0.240 & 0.542 \\
\hline RR rate $\min ,\left\llcorner V\left(\% \mathrm{~s}^{-1}\right)\right.$ & $-190 \pm 81$ & $-229 \pm 90$ & 0.132 & $-192 \pm 41$ & $-222 \pm 53$ & 0.348 & 0.956 & 0.881 \\
\hline LL rate $\max \left(\% \cdot s^{-1}\right)$ & $51 \pm 19$ & $71 \pm 17$ & 0.104 & $47 \pm 10$ & $58 \pm 10$ & 0.143 & 0.670 & 0.171 \\
\hline torsion rate $\min _{\min }\left({ }^{0} \cdot \mathrm{s}^{-1}\right)$ & $-24 \pm 6$ & $-43 \pm 13$ & 0.009 & $-28 \pm 9$ & $-28 \pm 7$ & 0.921 & 0.457 & 0.072 \\
\hline
\end{tabular}

$C C_{\min , L V}$ minimal left ventricular circumferencial strain, $R R_{\max , L V}$ maximal left ventricular radial strain, $L L_{\min , L V}$ minimal left ventricular longitudinal strain, torsion ${ }_{\text {max }}$

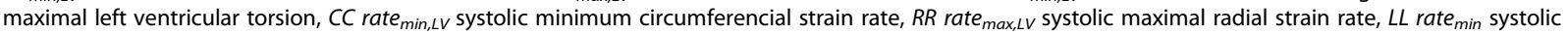
minimal longitudinal strain rate, torsion rate $\min _{\text {in }}$ systolic minimal torsion rate, $C C$ rate $_{\text {max }_{L} L V}$ early diastolic maximal circumferencial strain rate, $R R$ rate min, $L V$ early

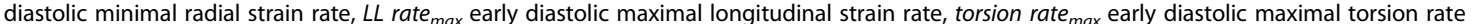
$p$ is related to the rest-stress comparison within each group. $p_{\text {rest }}$ and $p_{\text {stress }}$ relate to group comparisons at rest and stress, respectively

\section{Stereological analysis}

Samples of five DOCA and three control pigs were evaluated. Volume fractions of the interstitium $\left(\mathrm{V}_{\mathrm{V}}(\mathrm{int} / \mathrm{lv})\right.$ : controls, $21 \pm 2 \%$; DOCA, $19 \pm 2 \%$; $p=0.283$ ) and of blood vessels $\left(\mathrm{V}_{\mathrm{V}}(\mathrm{ves} / \mathrm{lv})\right.$ : controls, $4.4 \pm 1.3 \%$; DOCA, $5.5 \pm 0.4 \% ; p=0.092)$ did not differ between the DOCAsalt treated and control group. Volume fractions of collagen with respect to both the $\mathrm{LV}\left(\mathrm{V}_{\mathrm{V}}(\right.$ coll/lv $)$ : controls, $1.7 \pm 0.5 \%$; DOCA, $3.0 \pm 0.7 \% ; p=0.044)$ and the interstitium ( $\mathrm{V}_{\mathrm{V}}$ (coll/int): controls, $8 \pm 3 \%$; DOCA, $16 \pm 4 \%$; $p=0.025)$ were significantly increased in the DOCA group (Fig. 5). Total myocyte volume (V(myo/lv): controls, $67 \pm 1 \mathrm{ml}$; DOCA, $104 \pm 16 \mathrm{ml} ; p=0.009)$, total collagen volume $(\mathrm{V}(\mathrm{col} / \mathrm{lv})$ : controls, $1.5 \pm 0.4 \mathrm{ml}$; DOCA, $3.8 \pm 1.0 \mathrm{ml} ; p=0.011)$ and total blood vessel volume (V(ves/lv): controls, $3.7 \pm 1.1 \mathrm{ml}$; DOCA, $7.1 \pm$ $1.2 \mathrm{ml} ; p=0.012$ ) were higher in the DOCA pigs than in the control pigs.

\section{Discussion}

CMR at rest and during dobutamine stress allowed analysis and characterization of cardiac, cardiovascular and myocardial function in pigs without and with DOCA-salt treatment. Aside from LV hypertrophy, DOCA animals displayed alterations in myocardial muscle mechanics, left ventricular filling characteristics, left atrial volumes and function, and myocardial perfusion at rest and/or during stress. Significant elevation of collagen in the DOCA group shown by stereology could not be resolved by native $\mathrm{T} 1$ mapping.

\section{Left ventricular hypertrophy and myocardial alterations}

In accordance with previous studies, DOCA pigs developed hypertension and concentric LV hypertrophy, with a normal-sized LV chamber and increased LV muscle mass $[9,10,17]$. Stereological interstitial volume fraction was comparable in DOCA and control animals, indicating that hypertrophy in this early-stage HFpEF model results from enlargement of both cardiomyocytes and interstitial space. In the study by Schwarzl et al. [17], picrosirius red staining did not indicate higher levels of collagen in DOCA pigs compared to control animals. Stereological analysis in the present study revealed increased levels of collagen (i.e., a higher collagen volume relative to the interstitial space, relative to the LV myocardium and to the absolute volume). Notably, increased levels of collagen and reduced total-titin phosphorylation [17] in DOCA pigs could be interpreted as a sign of a transition from hypertensive heart disease to HFpEF [29-32].

Native T1 times did not resolve the higher myocardial collagen content documented by the stereological evaluation $[33,34]$. This can be understood by the fact that voxel-based evaluation of magnetic relaxation time maps displays an effective T1 time of all compartments in the voxel. An increased LV volume fraction of collagen tends to increase myocardial T1 times [33], whereas an increased volume fraction of cardiomyocytes should decrease T1. Even though not significant, lower native myocardial T1 times in early-stage HFpEF animals represent the larger compartment $\left(1-\mathrm{V}_{\mathrm{V}}(\mathrm{int} / \mathrm{lv})\right.$ in stereological analysis) of hypertrophied cardiomyocytes rather 

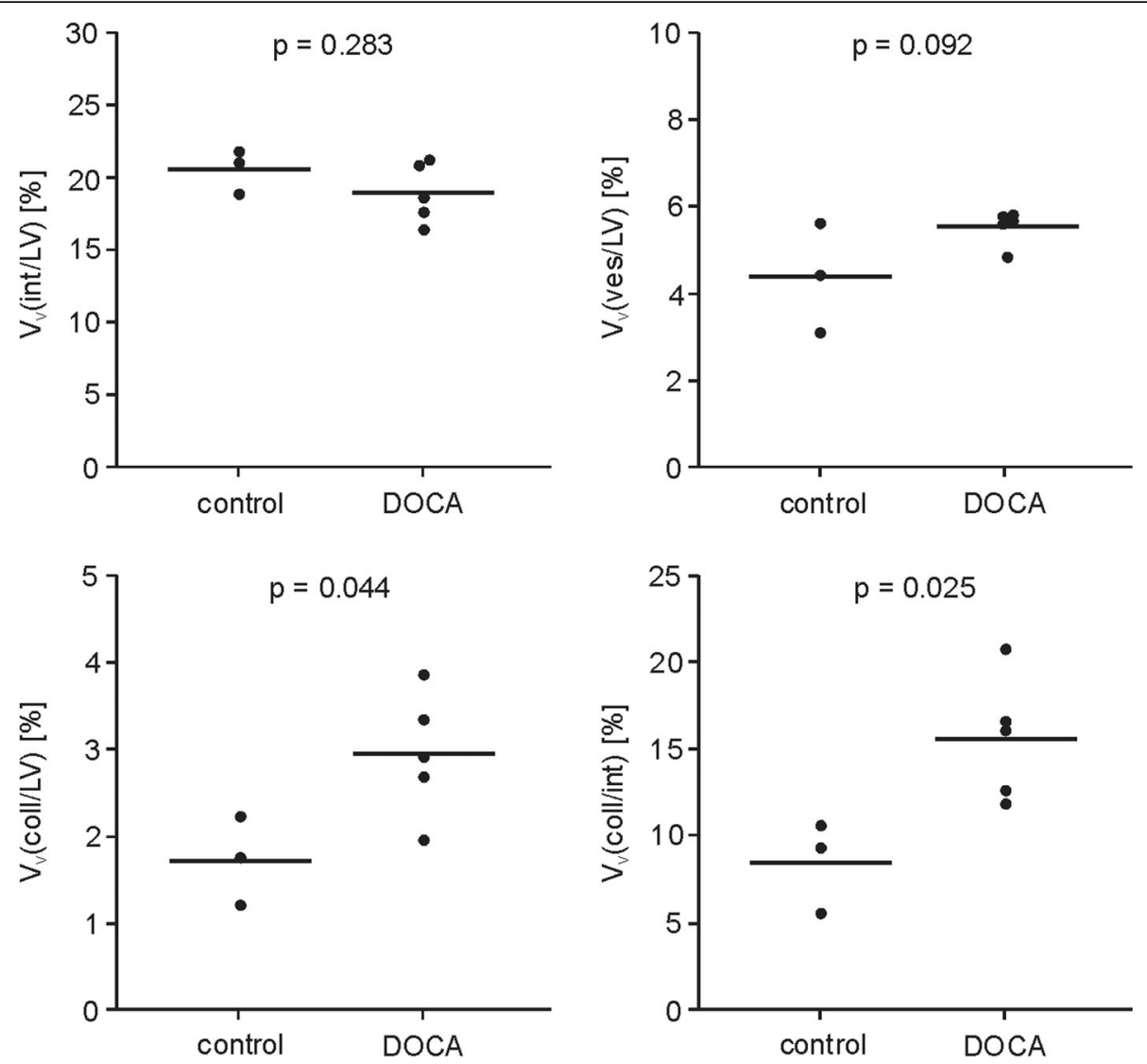

Fig. 5 Dot plots of volume fractions of the interstitium $V_{V}\left(\right.$ int/lv), of the blood vessels $V_{V}(v e s / l v)$, and of collagen $V_{V}($ coll//V) with respect to the $L V$ myocardium, as well as volume fraction of collagen with respect to the interstitium $V_{V}($ coll/int) in controls and DOCA pigs. Lines indicate mean values, $p$ values refer to $t$-test

than the elevated levels of collagen in the slightly smaller compartment of interstitium $\left(\mathrm{V}_{\mathrm{V}}\right.$ (int/lv) in stereological analysis) in a voxel.

\section{Blood supply and myocardial perfusion}

In accordance with other investigations of vessel wall thickening in DOCA pigs [12, 14], our study found significantly enlarged aortic cross-sectional areas and increased aortic vessel wall thickness in the DOCA group. In addition to this aortic remodeling, the absolute myocardial vessel volume compartment $\mathrm{V}(\mathrm{ves} / \mathrm{lv})$ was enlarged in DOCA pigs, which could be due to the increase of vessel wall thickness, number of coronary vessels, coronary vessel dilatation, or all together; microvascular rarefaction as found in HFpEF patients at higher levels of myocardial fibrosis [35] is, however, not directly supported.

Although the exact cause for the altered myocardial vessel volume compartment in DOCA pigs cannot be specified on the basis of stereological data, structural changes in the myocardial microvasculature are in line with the impairment of the myocardial perfusion reserve observed in DOCA pigs: Coronary sinus net forward volume was higher in DOCA pigs at rest maintaining normal global myocardial perfusion of the hypertrophic myocardium. During stress, myocardial perfusion in DOCA pigs increased mainly due to a rise in heart rate (indicated by the insignificant stress-to-rest difference of coronary sinus net forward volume), resulting in a significantly reduced myocardial perfusion reserve in DOCA pigs compared to controls. These findings at rest and stress were also reported in patients with HFpEF [36] and were attributed to microvascular dysfunction as well as a reduced vasodilator reserve $[36,37]$.

\section{Left ventricular and myocardial function}

During $\beta$-adrenergic stress, an adequate increase in LV ejection fraction and a decrease in ESV accounted for normal contractility reserves in both groups. However, EDV significantly decreased during stress in DOCA pigs, inhibiting stroke volume and cardiac index from properly increasing with the heart rate. A similar response was reported in patients with HFpEF during dynamic exercise [38, 39]. 
Echocardiographic studies in HFpEF patients document reduced longitudinal and circumferential strain [40] as well as failure to increase LV ejection fraction and global longitudinal strain rate during stress [41]. In our study, DOCA pigs with early-stage HFpEF did not show failure to increase LV ejection fraction during stress, but they demonstrated a significantly lower LL rate $_{\min }$ compared to control animals; thus systolic function - though normal at rest - showed signs of impairment during stress. These results are in accordance with findings in hypertensive patients with LV hypertrophy, where authors showed that systolic dysfunction may develop in parallel to diastolic dysfunction [40, 42, 43]. Moreover and in line with findings in patients with hypertensive LV hypertrophy [44], MAPSE was reduced in the DOCA group at rest but significantly increased during stress enabling adequate increase in LV ejection fraction with heart rate.

E' was significantly decreased in the DOCA group at rest and during dobutamine stress, and accordingly E/E' and $\left(E / E^{\prime}\right) / E D V$ ratios were higher in DOCA than in control animals. It was previously shown in HFPEF patients that E/E' correlates well with the LV end-diastolic pressure [39]. The significant higher E/E' in DOCA compared to control pigs at rest and during stress indicates slightly higher LV filling pressures in DOCA animals, which is up to statistical significance in accordance with the invasive results reported by Schwarzl et al. [17]. Decreased E' and increased (E/E')/EDV might be interpreted as marker for increased diastolic myocardial stiffening in DOCA pigs [32], caused by both, increased levels of collagen shown in the present study and reduced total-titin phosphorylation reported by Schwarzl et al. [17]. Similar changes in E' and (E/E')/EDV were observed also in HFpEF patients [32, 39, 45]. In DOCA pigs, increased (E/E')/EDV may further be related to the prolonged IVRT at rest [46, 47] and/or subtle stress-induced myocardial ischemia [48], as indicated by the lower global myocardial perfusion reserve during dobutamine in the hypertrophied LV myocardium in DOCA pigs.

Due to increased $\mathrm{D}$-wave peak velocities in the DOCA group, the pulmonary venous S/D ratio was significantly lower at rest in DOCA pigs than in control pigs. As LV relaxation is the main determinant of pulmonary venous flow $[49,50]$, observed pulmonary venous flow patterns in DOCA pigs again indicate altered LV relaxation. The observed failing of systolic and diastolic pulmonary venous peak velocities to increase during stress in the DOCA group could be due to a mild LA pressure increase $[17,50]$, which could in turn be related to the increased E/E' in DOCA animals.

LV torsion is known to be dependent on LV shape, and in LV concentric hypertrophy increased torsion is due to an increased lever arm for epicardial fibers [51]. Accordingly, torsion and systolic torsion rate $_{\max }$ were higher in DOCA than control pigs. Diastolic torsion rate $_{\min }$ significantly increased during $\beta$-adrenergic stimulation in the control group, indicating that intraventricular pressure gradients appropriately increased [52]. In DOCA animals, the difference in torsion rate $_{\min }$ between stress and rest failed to properly increase; this failure relates to reduced intraventricular pressure gradients and impairment of LV relaxation [53].

\section{Left atrium}

DOCA pigs showed significantly increased LA volumes at rest; this could be interpreted as a marker of altered diastolic function, LA pressure and early diastolic filling [54]. During stress, maximal LA volumes significantly decreased in the DOCA group (in parallel with EDV), augmenting impairment of LATEF. Melenovsky et al. [45] found that among various systolic, diastolic, and vascular function abnormalities seen in patients with $\mathrm{LV}$ hypertrophy and patients with HFpEF, LA dilatation and reduced LATEF were the most useful for discriminating between the two groups.

\section{Limitations}

Several limitations of the present study need to be acknowledged. The study had a small sample size; therefore it was not possible to assess correlations between studied parameters. Moreover, samples for stereological analysis were collected in a sub-group of animals only from the LV lateral wall and, for reasons of feasibility, not by a random sampling scheme.

Cardiac, myocardial and vascular CMR parameters were obtained for comparison from DOCA-treated and non-DOCA treated landrace pigs in anesthesia. As there were no obvious cardiovascular malformations and no outliers in the studied parameters, it is quite likely that all the non-DOCA treated pigs represent a normal collective. Neither the effect of the subcutaneous implantation procedure nor the overall effects of anesthesia were controlled in the current study.

All CMR measurements were performed under mechanical ventilation, which reduced limitations on temporal resolution of cine acquisitions, in particular. The fact that diastolic functional parameters like E', E/A or IVRT compare well with echocardiographic normal values in pigs $[55,56]$ might be interpreted as sign for an adequate choice of temporal resolution of cine sequences to unmask possible differences in diastolic function of DOCA and control pigs. Breathing motion was typically suppressed by averaging, except for the MOLLI sequence. Automated motion correction, however, enabled appropriate reconstruction of T1 maps. 4D flow data were acquired with one velocity encoding 
optimized for LV intra-cavity blood flow, and all flow results were determined a posteriori from this dataset. The multiple acquisitions of smaller data sets with optimized velocity encoding and optimized resolution might have improved the accuracy of results but would have further prolonged investigation time.

The comprehensive imaging protocol allowed the investigation of only one stress level. In accordance with results found in HFpEF patients [57], chronotropic responsiveness to low-dose dobutamine was slightly reduced in DOCA pigs compared to controls, necessitating increased dobutamine infusion rates for DOCA pigs when targeting a heart rate increase of approximately $25 \%$ in all subjects. While equalizing chronotropic responses during stress in DOCA and control pigs, dobutamine dosage and its inotropic, lusitropic and vasodilative effects were not controlled. Continuous and monotone responses of myocardial functional parameters found at small increases of infusion rates of dobutamine in the low-dose regime in HFpEF and control patients [57] suggest, that only small differences in observed stress-to-rest reserves might be expected compared to applying constant dobutamine infusion rates in all pigs.

Finally, invasive intra-cardiac hemodynamic measurements were not performed during CMR examinations, as appropriate MR-compatible equipment was not available.

\section{Conclusions}

The present study documents numerous alterations in CMR-derived indices of cardiac and myocardial function at rest and during stress in pigs with DOCA-salt induced early-stage HFpEF. LA enlargement, metrics of myocardial tissue velocity, pulmonary venous and transmitral blood flow velocities presented as potential CMR markers of early-stage HFpEF at rest, highlighting the important role of LA impairment in the development of HFpEF. Inadequate increases in myocardial perfusion reserve and cardiac index during dobutamine stress may prove to be useful new CMR metrics for the diagnosis of HFpEF, and could probably account for exercise intolerance in early stages of disease. Myocardial T1 mapping, however, could not detect elevated levels of myocardial collagen found by stereology in DOCA pigs.

\footnotetext{
Abbreviations

A: Late diastolic mitral peak blood flow velocity; AT: Acceleration time; AVC: Aortic valve closure; AVO: Aortic valve opening; AWT: Aortic wall thickness; BSA: Body surface area; bSSFP: Balanced steady-state free precession; CC: Circumferential strain; CMR: Cardiovascular magnetic resonance; D: Early diastolic pulmonary venous peak velocity; DT: Deceleration time; E: Early diastolic mitral peak blood flow velocity; E': Early diastolic myocardial tissue velocity; ECG: Electrocardiographical; EDV: LV end-diastolic volume; ESV: LV end-systolic volume; FLASH: Fast low angle shot; HFpEF: Heart failure with preserved ejection fraction; IVCT: Isovolumetric contraction time; IVRT: Isovolumetric relaxation time; LA: Left atrium; LATEF: Total left atrial ejection fraction; LAV: LA volume; LL: Longitudinal strain; LV: Left ventricle; LVET: Left ventricular ejection time; LVMM: Left ventricular muscle mass;
}

MAPSE: Mitral annular plane systolic excursion; MOLLI: Modified Look-Locker inversion recovery; MVC: Mitral valve closure; MVO: Mitral valve opening; PER: Peak ejection rate; PET: Peak ejection time; PFR : Late diastolic peak filling rate; $P F R_{E}$ : Early diastolic peak filling rate; $\mathrm{PFT}_{\mathrm{A}}$ : Late diastolic peak filling time; $\mathrm{PFT}_{\mathrm{E}}$ : Early diastolic peak filling time; RR: Radial strain; S: Systolic pulmonary venous peak blood flow velocity; SPAMM: Spatial modulation of magnetization; t: time; V(coll,Iv): Total myocardial collagen content; $\mathrm{V}(\mathrm{myo}, \mathrm{lv})$ : Total myocardial myocyte content; $\mathrm{V}(\mathrm{ves}, \mathrm{lv})$ : Total myocardial blood vessel content; $V_{v}($ coll//int): Volume fraction of collagen fibrils related to the interstitium; $V_{V}($ coll//lv): Volume fraction of collagen fibrils related to the left ventricle; $V_{V}($ int/lv): Volume fraction of the interstitium related to the left ventricle; $V_{V}(m y o, I v)$ : Volume fraction of cardiomyocytes related to the left ventricle; $V_{v}(v e s / l v)$ : Volume fraction of blood vessels related to the left ventricle

\section{Acknowledgements}

The authors thank Ada Muellner, MSc for reviewing the manuscript.

\section{Funding}

This work was partly supported by a grant from the European Union Seventh Framework Program (FP7/2007-2013; Grant Agreement HEALTHF2-2010-261057, EUTR). A.A. was supported by the Austrian Science Fund's PhD-programme "DK-MOLIN - Molecular Fundamentals of Inflammation" (FWF; W 1218). G.A. was supported by the funds of the Oesterreichische Nationalbank, Anniversary Fund (Grant Number 141223). CM was supported by the BMBF via the German Center for Lung Research (DZL) and the DFG via the Cluster of Excellence REBIRTH.

\section{Authors' contributions}

UR, study design, data acquisition and analysis, manuscript preparation and editing; GR, study design, data acquisition and analysis, manuscript preparation and editing; MM, study design, data acquisition; manuscript editing; GA, study design, data analysis; manuscript editing; JS, study design, data analysis; manuscript editing; AA, study design, data acquisition; manuscript editing; AR, study design, data analysis; manuscript editing; AFS, Study design, manuscript editing; AG, Study design, manuscript editing; CM, study design, data analysis; manuscript editing; DS, Study design, manuscript editing; HP, study design, data acquisition; manuscript editing; BP, Study design, manuscript editing; MF, study design, manuscript editing. All authors read and approved the final manuscript.

\section{Competing interests}

GR, AG and AFS are employed by Siemens Healthcare. The authors declare that they have no competing interests.

\section{Author details}

${ }^{1}$ Division of General Radiology, Department of Radiology, Medical University of Graz, Auenbruggerplatz 9/P, 8036 Graz, Austria. ${ }^{2}$ Siemens Healthcare, Graz, Austria. ${ }^{3}$ Division of Cardiology, Department of Internal Medicine, Medical University of Graz, Graz, Austria. ${ }^{4}$ Hannover Medical School, Institute of Functional and Applied Anatomy, Hannover, Germany. ${ }^{5}$ Department of Internal Medicine and Cardiology, Campus Virchow Klinikum, Charité University Medicine Berlin, Berlin, Germany. ${ }^{6}$ Siemens Healthcare GmBH, Erlangen, Germany. 'Department of Internal Medicine and Cardiology, German Heart Center Berlin, Berlin, Germany. ${ }^{8}$ Berlin Institute of Health, Berlin, Germany.

Received: 10 August 2016 Accepted: 14 September 2016

Published online: 30 September 2016

References

1. Nichols GA, Reynolds K, Kimes TM, Rosales AG, Chan WW. Comparison of risk of Re-hospitalization, all-cause mortality, and medical care resource utilization in patients with heart failure and preserved versus reduced ejection fraction. Am J Cardiol. 2015;116(7):1088-92.

2. Bhatia RS, Tu JV, Lee DS, Austin PC, Fang J, Haouzi A, Gong Y, Liu PP. Outcome of heart failure with preserved ejection fraction in a populationbased study. N Engl J Med. 2006;355(3):260-9.

3. Shah AM, Pfeffer MA. The many faces of heart failure with preserved ejection fraction. Nat Rev Cardiol. 2012;9(10):555-6. 
4. Shah SJ, Katz DH, Selvaraj S, Burke MA, Yancy CW, Gheorghiade M, Bonow RO, Huang CC, Deo RC. Phenomapping for novel classification of heart failure with preserved ejection fraction. Circulation. 2015;131(3):269-79.

5. Conceicao G, Heinonen I, Lourenco AP, Duncker DJ, Falcao-Pires I. Animal models of heart failure with preserved ejection fraction. Neth Heart J. 2016;24(4):275-86

6. Terris JM, Berecek KH, Cohen EL, Stanley JC, Whitehouse Jr WM, Bohr DF. Deoxycorticosterone hypertension in the pig. Clin Sci Mol Med Suppl. 1976;3:303s-5.

7. Miller 2nd AW, Bohr DF, Schork AM, Terris JM. Hemodynamic responses to DOCA in young pigs. Hypertension. 1979;1(6):591-7.

8. Cohen DM, Grekin RJ, Mitchell J, Rice WH, Bohr DF. Hemodynamic, endocrine, and electrolyte changes during sodium restriction in DOCA hypertensive pigs. Hypertension. 1980;2(4):490-6.

9. Sweadner KJ, Herrera VL, Amato S, Moellmann A, Gibbons DK, Repke KR. Immunologic identification of $\mathrm{Na}+\mathrm{K}(+)$-ATPase isoforms in myocardium. Isoform change in deoxycorticosterone acetate-salt hypertension. Circ Res. 1994;74(4):669-78.

10. Terris JM, Simmonds RC. The Yucatan miniature swine: an improved pig model for the study of desoxycorticosterone-acetate (DOCA) and aldosterone hypertension. Proc Soc Exp Biol Med. 1982;171(1):79-82

11. Berecek KH, Bohr DF. Structural and functional changes in vascular resistance and reactivity in the deoxycorticosterone acetate (DOCA)hypertensive pig. Circ Res. 1977;40(5 Suppl 1):1146-52.

12. Berecek KH, Bohr DF. Whole body vascular reactivity during the development of deoxycorticosterone acetate hypertension in the pig. Circ Res. 1978;42(6):764-71.

13. Walterhouse DO, Reinish LW, Mitchell J, Bohr DF. Aortic stiffness in the DOCA-hypertensive pig. Clin Physiol Biochem. 1984;2(4):146-53.

14. Kamm KE, Gerthoffer WT, Murphy RA, Bohr DF. Mechanical properties of carotid arteries from DOCA hypertensive swine. Hypertension. 1989;13(2):102-9.

15. Webb RC. Potassium relaxation of vascular smooth muscle from DOCA hypertensive pigs. Hypertension. 1982;4(5):609-19.

16. Ciccone CD, Zambraski EJ. Effects of acute renal denervation on kidney function in deoxycorticosterone acetate-hypertensive swine. Hypertension. 1986;8(10):925-31.

17. Schwarzl M, Hamdani N, Seiler S, Alogna A, Manninger M, Reilly S, Zirngast B, Kirsch A, Steendijk P, Verderber J, Zweiker D, Eller P, Hofler G, Schauer S, Eller K, Maechler H, Pieske BM, Linke WA, Casadei B, Post H. A porcine model of hypertensive cardiomyopathy: implications for heart failure with preserved ejection fraction. Am J Physiol Heart Circ Physiol. 2015;309(9):H1407-18.

18. Hunt SA, Abraham WT, Chin MH, Feldman AM, Francis GS, Ganiats TG, Jessup M, Konstam MA, Mancini DM, Michl K, Oates JA, Rahko PS, Silver MA, Stevenson LW, Yancy CW, American College of Cardiology Foundation, American Heart Association. 2009 focused update incorporated into the ACC/AHA 2005 guidelines for the diagnosis and management of heart failure in adults a report of the American College of Cardiology Foundation/ American Heart Association Task Force on Practice Guidelines Developed in Collaboration with the International Society for Heart and Lung Transplantation. J Am Coll Cardiol. 2009;53(15):e1-90.

19. Friedrich MG, Bucciarelli-Ducci C, White JA, Plein S, Moon JC, Almeida AG, Kramer CM, Neubauer S, Pennell DJ, Petersen SE, Kwong RY, Ferrari VA, SchulzMenger J, Sakuma H, Schelbert EB, Larose E, Eitel I, Carbone I, Taylor AJ, Young A, de Roos A, Nagel E. Simplifying cardiovascular magnetic resonance pulse sequence terminology. J Cardiovasc Magn Reson. 2014;16:3960.

20. Treibel TA, White SK, Moon JC. Myocardial tissue characterization: histological and pathophysiological correlation. Curr Cardiovasc Imaging Rep. 2014;7(3):9254.

21. McMurray JJ, Adamopoulos S, Anker SD, Auricchio A, Bohm M, Dickstein K, Falk V, Filippatos G, Fonseca C, Gomez-Sanchez MA, Jaarsma T, Kober L, Lip GY, Maggioni AP, Parkhomenko A, Pieske BM, Popescu BA, Ronnevik PK, Rutten FH, Schwitter J, Seferovic P, Stepinska J, Trindade PT, Voors AA, Zannad F, Zeiher A, Task Force for the Diagnosis and Treatment of Acute and Chronic Heart Failure 2012 of the European Society of Cardiology, Bax JJ, Baumgartner H, Ceconi C, Dean V, Deaton C, Fagard R, Funck-Brentano C, Hasdai D, Hoes A, Kirchhof P, Knuuti J, Kolh P, McDonagh T, Moulin C, Popescu BA, Reiner Z, Sechtem U, Sirnes PA, Tendera M, Torbicki A, Vahanian A, Windecker S, McDonagh T, Sechtem U, Bonet LA, Avraamides P, Ben Lamin HA, Brignole M, Coca A, Cowburn P, Dargie H, Elliott P, Flachskampf FA, Guida GF, Hardman S, lung B, Merkely B, Mueller C, Nanas
JN, Nielsen OW, Orn S, Parissis JT, Ponikowski P, ESC Committee for Practice Guidelines. ESC guidelines for the diagnosis and treatment of acute and chronic heart failure 2012: The Task Force for the Diagnosis and Treatment of Acute and Chronic Heart Failure 2012 of the European Society of Cardiology. Developed in collaboration with the Heart Failure Association (HFA) of the ESC. Eur J Heart Fail. 2012;14(8):803-69.

22. Charoenpanichkit $\mathrm{C}$, Hundley WG. The 20 year evolution of dobutamine stress cardiovascular magnetic resonance. J Cardiovasc Magn Reson. 2010;12:59.

23. Kelley KW, Curtis SE, Marzan GT, Karara HM, Anderson CR. Body surface area of female swine. J Anim Sci. 1973;36(5):927-30.

24. Schulz-Menger J, Bluemke DA, Bremerich J, Flamm SD, Fogel MA, Friedrich MG, Kim RJ, von Knobelsdorff-Brenkenhoff F, Kramer CM, Pennell DJ, Plein S, Nagel E. Standardized image interpretation and post processing in cardiovascular magnetic resonance: Society for Cardiovascular Magnetic Resonance (SCMR) board of trustees task force on standardized post processing. J Cardiovasc Magn Reson. 2013;15:35.

25. Lavine $\mathrm{SJ}$. Index of myocardial performance is afterload dependent in the normal and abnormal left ventricle. J Am Soc Echocardiogr. 2005;18(4):342-50.

26. Sievers B, Kirchberg S, Addo M, Bakan A, Brandts B, Trappe HJ. Assessment of left atrial volumes in sinus rhythm and atrial fibrillation using the biplane area-length method and cardiovascular magnetic resonance imaging with TrueFISP. J Cardiovasc Magn Reson. 2004;6(4):855-63.

27. Schwitter J, DeMarco T, Kneifel S, von Schulthess GK, Jorg MC, Arheden H, Ruhm S, Stumpe K, Buck A, Parmley WW, Luscher TF, Higgins CB. Magnetic resonance-based assessment of global coronary flow and flow reserve and its relation to left ventricular functional parameters: a comparison with positron emission tomography. Circulation. 2000;101(23):2696-702.

28. Kellman P, Wilson JR, Xue H, Ugander M, Arai AE. Extracellular volume fraction mapping in the myocardium, part 1: evaluation of an automated method. J Cardiovasc Magn Reson. 2012;14:63.

29. Konstam MA, Kramer DG, Patel AR, Maron MS, Udelson JE. Left ventricular remodeling in heart failure: current concepts in clinical significance and assessment. JACC Cardiovasc Imaging. 2011;4(1):98-108.

30. Santos M, Shah AM. Alterations in cardiac structure and function in hypertension. Curr Hypertens Rep. 2014;16(5):428.

31. Nadruz W. Myocardial remodeling in hypertension. J Hum Hypertens. 2015;29(1):1-6.

32. Zile MR, Baicu CF, Ikonomidis JS, Stroud RE, Nietert PJ, Bradshaw AD, Slater R, Palmer BM, Van Buren P, Meyer M, Redfield MM, Bull DA, Granzier HL, LeWinter MM. Myocardial stiffness in patients with heart failure and a preserved ejection fraction: contributions of collagen and titin. Circulation. 2015:131(14):1247-59.

33. Bull S, White SK, Piechnik SK, Flett AS, Ferreira VM, Loudon M, Francis JM, Karamitsos TD, Prendergast BD, Robson MD, Neubauer S, Moon JC, Myerson SG. Human non-contrast T1 values and correlation with histology in diffuse fibrosis. Heart. 2013;99(13):932-7.

34. Su MY, Lin LY, Tseng YH, Chang CC, Wu CK, Lin JL, Tseng WY. CMR-verified diffuse myocardial fibrosis is associated with diastolic dysfunction in HFpEF. JACC Cardiovasc Imaging. 2014;7(10):991-7.

35. Mohammed SF, Hussain S, Mirzoyev SA, Edwards WD, Maleszewski JJ, Redfield MM. Coronary microvascular rarefaction and myocardial fibrosis in heart failure with preserved ejection fraction. Circulation. 2015;131(6): 550-9.

36. Kato S, Saito N, Kirigaya H, Gyotoku D, linuma N, Kusakawa Y, Iguchi K, Nakachi T, Fukui K, Futaki M, Iwasawa T, Kimura K, Umemura S. Impairment of coronary flow reserve evaluated by phase contrast cine-magnetic resonance imaging in patients with heart failure with preserved ejection fraction. J Am Heart Assoc. 2016;5(2):10.1161/JAHA.115.002649.

37. Borlaug BA, Melenovsky V, Russell SD, Kessler K, Pacak K, Becker LC, Kass DA. Impaired chronotropic and vasodilator reserves limit exercise capacity in patients with heart failure and a preserved ejection fraction. Circulation. 2006;114(20):2138-47.

38. Borlaug BA, Jaber WA, Ommen SR, Lam CS, Redfield MM, Nishimura RA. Diastolic relaxation and compliance reserve during dynamic exercise in heart failure with preserved ejection fraction. Heart. 2011;97(12):964-9.

39. Kasner M, Sinning D, Burkhoff D, Tschope C. Diastolic pressure-volume quotient (DPVQ) as a novel echocardiographic index for estimation of LV stiffness in HFpEF. Clin Res Cardiol. 2015;104(11):955-63.

40. Kraigher-Krainer E, Shah AM, Gupta DK, Santos A, Claggett B, Pieske B, Zile MR, Voors AA, Lefkowitz MP, Packer M, McMurray JJ, Solomon SD, PARAMOUNT Investigators. Impaired systolic function by strain imaging 
in heart failure with preserved ejection fraction. J Am Coll Cardiol. 2014;63(5):447-56.

41. Henein M, Morner S, Lindmark K, Lindqvist P. Impaired left ventricular systolic function reserve limits cardiac output and exercise capacity in HFpEF patients due to systemic hypertension. Int I Cardiol. 2013;168(2):1088-93.

42. Wachtell K, Papademetriou V, Smith G, Gerdts E, Dahlof B, Engblom E, Aurigemma GP, Bella JN, Ibsen H, Rokkedal J, Devereux RB. Relation of impaired left ventricular filling to systolic midwall mechanics in hypertensive patients with normal left ventricular systolic chamber function: the Losartan Intervention for Endpoint Reduction in Hypertension (LIFE) study. Am Heart J. 2004;148(3):538-44.

43. de Simone G, Ganau A, Roman MJ, Devereux RB. Relation of left ventricular longitudinal and circumferential shortening to ejection fraction in the presence or in the absence of mild hypertension. J Hypertens. 1997:15(9):1011-7.

44. Aurigemma GP, Silver KH, Priest MA, Gaasch WH. Geometric changes allow normal ejection fraction despite depressed myocardial shortening in hypertensive left ventricular hypertrophy. J Am Coll Cardiol. 1995;26(1):195-202.

45. Melenovsky V, Borlaug BA, Rosen B, Hay I, Ferruci L, Morell CH, Lakatta EG, Najjar SS, Kass DA. Cardiovascular features of heart failure with preserved ejection fraction versus nonfailing hypertensive left ventricular hypertrophy in the urban Baltimore community: the role of atrial remodeling/ dysfunction. J Am Coll Cardiol. 2007;49(2):198-207.

46. Yu CM, Lin H, Yang H, Kong SL, Zhang Q, Lee SW. Progression of systolic abnormalities in patients with "isolated" diastolic heart failure and diastolic dysfunction. Circulation. 2002;105(10):1195-201.

47. Kono M, Kisanuki A, Ueya N, Kubota K, Kuwahara E, Takasaki K, Yuasa T, Mizukami N, Miyata M, Tei C. Left ventricular global systolic dysfunction has a significant role in the development of diastolic heart failure in patients with systemic hypertension. Hypertens Res. 2010;33(11):1167-73.

48. Phan TT, Abozguia K, Nallur Shivu G, Mahadevan G, Ahmed I, Williams L, Dwivedi G, Patel K, Steendijk P, Ashrafian H, Henning A, Frenneaux M. Heart failure with preserved ejection fraction is characterized by dynamic impairment of active relaxation and contraction of the left ventricle on exercise and associated with myocardial energy deficiency. J Am Coll Cardiol. 2009;54(5):402-9.

49. Masuyama T, Lee JM, Nagano R, Nariyama K, Yamamoto K, Naito J, Mano T, Kondo H, Hori M, Kamada T. Doppler echocardiographic pulmonary venous flow-velocity pattern for assessment of the hemodynamic profile in acute congestive heart failure. Am Heart J. 1995;129(1):107-13.

50. Barbier P, Solomon S, Schiller NB, Glantz SA. Determinants of forward pulmonary vein flow: an open pericardium pig model. J Am Coll Cardiol. 2000;35(7):1947-59.

51. Young AA, Cowan BR. Evaluation of left ventricular torsion by cardiovascular magnetic resonance. J Cardiovasc Magn Reson. 2012;14:49.

52. Burns AT, La Gerche A, Maclsaac Al, Prior DL. Augmentation of left ventricular torsion with exercise is attenuated with age. J Am Soc Echocardiogr. 2008:21(4):315-20.

53. Notomi Y, Martin-Miklovic MG, Oryszak SJ, Shiota T, Deserranno D, Popovic ZB, Garcia MJ, Greenberg NL, Thomas JD. Enhanced ventricular untwisting during exercise: a mechanistic manifestation of elastic recoil described by Doppler tissue imaging. Circulation. 2006;113(21):2524-33.

54. Takemoto Y, Barnes ME, Seward JB, Lester SJ, Appleton CA, Gersh BJ, Bailey $K R$, Tsang TS. Usefulness of left atrial volume in predicting first congestive heart failure in patients $>$ or $=65$ years of age with well-preserved left ventricular systolic function. Am J Cardiol. 2005;96(6):832-6.

55. Paslawska U, Noszczyk-Nowak A, Paslawski R, Janiszewski A, Kiczak L, Zysko D, Nicpon J, Jankowska EA, Szuba A, Ponikowski P. Normal electrocardiographic and echocardiographic (M-mode and twodimensional) values in Polish Landrace pigs. Acta Vet Scand. 2014;56:54.

56. Rienzo M, Bizé A, Pongas D, Michineau S, Melka J, Chan HL, Sambin L, Su JB, Dubois-Randé JL, Hittinger L, Berdeaux A, Ghaleh B. Impaired left ventricular function in the presence of preserved ejection in chronic hypertensive conscious pigs. Basic Res Cardiol. 2012;107:298.

57. Norman HS, Oujiri J, Larue SJ, Chapman CB, Margulies KB, Sweitzer NK. Decreased cardiac functional reserve in heart failure with preserved systolic function. J Card Fail. 2011;17(4):301-8. 